\title{
Doping effects on the structural and optical properties of GaN
}

\author{
Sergey Khromov
}

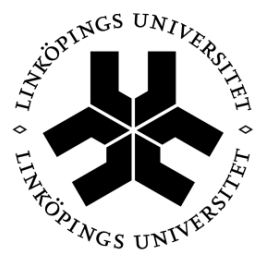

\section{Linköping University \\ INSTITUTE OF TECHNOLOGY}

Thin Film Physics Division

Department of Physics, Chemistry, and Biology (IFM)

Linköping University

SE-581 83 Linköping, Sweden 
(C) Sergey Khromov

ISBN: 978-91-7519-483-7

ISSN 0345-7524

Printed by LiU-Tryck

Linköping, Sweden, 2013 


\section{ABSTRACT}

Today there is a strong drive towards higher efficiency light emitters and devices for power electronics based on $\mathrm{GaN}$ and its ternary compounds. Device performance can be improved in several ways on the material level. Development of bulk GaN to substitute sapphire and SiC as substrate materials can allow lower defect density epitaxial GaN layers to be grown. Using nonpolar homoepitaxial layers alleviates the problem of polarization fields present in polar GaN epilayers. This thesis advances the field by attacking outstanding problems related to doping and its influence on structural and optical properties of GaN. Optical and structural investigations were performed on bulk GaN grown by halide vapor phase epitaxy (HVPE) and on polar and nonpolar epitaxial GaN grown by metal organic chemical vapor deposition (MOCVD), doped with different impurities: $\mathrm{Mg}, \mathrm{Si}, \mathrm{O}$ or C. Optical characterization was done using photoluminescence (PL), time-resolved photoluminescence (TRPL), and cathodoluminescence (CL) in-situ scanning electron microscope, whereas structural properties were studied by means of transmission electron microscopy (TEM) and atom probe tomography (APT).

A correlation between $\mathrm{Mg}$ doping levels and stacking fault (SF) concentration in highly $\mathrm{Mg}$-doped $c$-plane homoepitaxial $\mathrm{GaN}$ layers is found. Increasing $\mathrm{Mg}$ concentrations, from $2 \times 10^{18} \mathrm{~cm}^{-3}$ to $5 \times 10^{19} \mathrm{~cm}^{-3}$, coincides with increasing density of small, 3-10 $\mathrm{nm}$-sized, SFs. Emission lines ascribed to SFs are observed in CL in all the studied samples. The observed SF-related luminescence can be explained by a model where $\mathrm{Mg}$ atoms interacting with the nearby SF changes the confinement for holes and leads to a pronounced defectrelated luminescence. Non-polar $m$-plane homoepitaxial $\mathrm{GaN}$ layers with $\mathrm{Mg}$ concentration of $2 \times 10^{18} \mathrm{~cm}^{-3}$ and $3 \times 10^{19} \mathrm{~cm}^{-3}$ exhibits high density of basal SFs as well as a number of prismatic SFs. Instead of normally observed in nonpolar GaN SF-related broad lines several sharp lines are detected in the 3.36-3.42 eV region. Their relation to donor-acceptor pair recombination (DAP) was dismissed by calculating the DAP energies and fitting with the measured spectra. The sharp lines are tentatively explained by some impurities bound to point defects or SFs. The origin of two Mg related acceptor bound exciton (ABE) peaks in the emission spectra is also proposed: narrower $\mathrm{ABE} 1$ peak at $3.466 \mathrm{eV}$ is identified as coming from a substitutional $\mathrm{Mg}$ atom. Broader emission at $3.454 \mathrm{eV}$ is deemed to be coming from a $\mathrm{Mg}$ acceptor atom perturbed by a nearby SF. Additionally, $\mathrm{Mg}$ cluster formation in the highest doped sample $\left([\mathrm{Mg}]=1 \times 10^{20} \mathrm{~cm}^{-3}\right)$ was revealed by APT.

Simultaneous doping by $\mathrm{Si}$ and $\mathrm{O}$ was studied for HVPE grown bulk GaN. Doping with $\mathrm{O}$ concentration from $10^{17} \mathrm{~cm}^{-3}$ leads to a decrease in the Si concentration to less than $10^{16} \mathrm{~cm}^{-3}$. Si incorporation is believed to be suppressed by the competing Ga-vacancy-O incorporation process. Bandgap narrowing by $6 \mathrm{meV}$ due to high doping was observed. Donor bound exciton (DBE) lifetime was obtained from TPRL experimental data and it is found to decrease with increasing doping. In non-polar $m$-plane homoepitaxial $\mathrm{GaN} \mathrm{Si}$ doping influences the SF-related luminescence. At moderate Si concentrations excitons are bound to 
the impurity atoms or impurity-SF complex. Proximity of impurity atoms changes the potential for SF creating localization for charge carriers resulting in SF-related emission. At dopant concentrations higher than the Mott limit screening destroys the carrier interaction and, thus, the exciton localization at impurity-SF complex.

Finally, C-doped HVPE grown bulk GaN layers were studied by TEM, CL, and TRPL. Enhanced yellow line (YL) luminescence was observed with increasing $\mathrm{C}$ doping. Stability of YL in a wide temperature range $(5-300 \mathrm{~K})$ confirms that $\mathrm{YL}$ is due to a deep defect, likely $\mathrm{C}_{\mathrm{N}}-\mathrm{O}_{\mathrm{N}}$ complex. Low-temperature CL mapping reveals a pit-like structure with different luminescence properties in different areas. DBE emission dominates in CL spectra within the pits while in pit-free areas, in contrast, two ABE lines typical for Mg-doped $\mathrm{GaN}$ are observed. 


\section{POPULÄRVETENSKAPLIG SAMMANFATTNING}

Ungefär $20 \%$ av all elektricitet som produceras i världen används till belysning. Det betyder att vi kommer att spara mycket energi om vi ersätter nuvarande lågeffektiva glödlampor med starka vita lysdioder (LED), dessutom kommer utsläpp av koldioxid på planeten att minskas. Detta förklarar orsaken till den enorma utvecklingen av LED-industri som har skett under de sista 20 åren.

En lysdiod är en elektronisk komponent som avger ljus när en elektrisk ström leds i framåtriktningen. Den enklaste typen av diod består av två skikt av halvledarmaterial. Halvledarmaterial leder elektrisk ström dåligt men genom att dopa materialet med små koncentrationer av så kallade dopämnen kan man påverka ledningsförmågan. Dopatomerna kan ge extra elektroner till halvledarmaterialet eller binda elektroner till sig. När en elektron binds, skapas ett så kallat hål (avsaknad av elektron) som också kan leda ström. Materialet som har ett överskott av elektroner kallas för n-typ material och den andra, som har ett underskott av elektroner, - p-typ material. Skiktet där ett p-dopade material övergår till ett ndopade material kallas för en pn-övergång. Där kan elektroner och hål möta varandra, annihilera och i denna process utstrålas ljus. Genom att använda sig av olika typer av halvledarmaterial kan man skapa lysdioder som lyser i olika färger. Man har upptäckt att man kan tillverka högeffektiva blåa lysdioder i galliumnitrid ( $\mathrm{GaN}$ ) som kan användas som belysningskälla. Genom att låta det blåa ljuset excitera ett fosforskikt kan man omvandla det till vitt ljus. Vita lysdioder baserade på GaN finns redan på marknaden men deras effektivitet och prestanda kan fortfarande betydligt förbättras. Med en förbättrad galliumnitridteknologi kan vi förvänta oss en längre livstid och högre verkningsgrad hos lysdioderna.

Denna avhandling fokuserar på karakteriseringen av tunna och tjocka skikt av GaN som är viktiga för framställning av energisnåla vita lysdioder. Syftet med den forskningen var att få bättre förståelse hur dopning påverkar optiska och strukturella egenskaper hos GaN. Studierna har utförts med hjälp av flera mikroskopiska tekniker, som till exempel transmissionselektronmikroskopi och atomsondtomografi med nära nog atomär upplösning samt med optisk spektroskopi i form av fotoluminescens och katodoluminescens.

Dopning av GaN-skikten med magnesium, kol, kisel och syre har utforskats här. Proverna som har studerats var av både polär och icke-polär kristallorientering. Den sistnämnda orienteringen är viktig för tillverkning av LED-baserad på icke-polär GaN med bättre verkningsgrad. I det arbetet har jag studerat bland annat material som odlas med olika gasfasmetoder på substrat av GaN självt. Detta ledde till en framgångsrik framställning av GaN-skikt med en överlägsen strukturell kvalitet med färre defekter och lägre mekaniska spänningar i materialet. 


\section{PREFACE}

This Doctoral Thesis is a result of four and a half years' work during my $\mathrm{Ph}$. D. studies in the Thin Film Physics Group at Linköping University. The work is partially based on my Licentiate Thesis (Licentiate Thesis No. 1520, Linköping Studies in Science and Technology: The Effect of Mg Doping on Optical and Structural Properties of GaN). The

project was financed by the Swedish Energy Agency and the Swedish Research Council (VR). The results are presented in seven included papers preceded by the introduction.

Linköping, November 2013 


\section{INCLUDED PAPERS}

1. Luminescence related to high density of Mg-induced stacking faults in homoepitaxially grown GaN

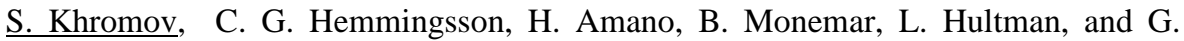
Pozina

Physical Review B 84, 075324 (2011)

I contributed to planning, performed large part of characterization (TEM, CL), and wrote the first version of the manuscript.

2. Optical and structural studies of homoepitaxially grown m-plane GaN

S. Khromov, B. Monemar, V. Avrutin, Xing Li, H.Morkoc, L. Hultman, and G. Pozina

Applied Physics Letters 100, 172108 (2012)

I contributed to planning, performed large part of characterization (TEM, CL), and wrote the first version of the manuscript.

\section{Luminescence of Acceptors in Mg-Doped GaN}

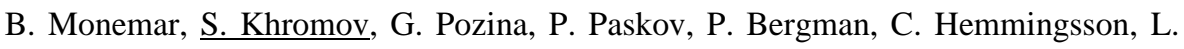
Hultman, H. Amano, V. Avrutin, Xing Li, and H. Morkoç

Japanese Journal of Applied Physics 52, $08 J J 03$ (2013)

I took part in planning, characterization, and discussion of the manuscript.

4. Atom probe tomography study of $\mathrm{Mg}$ doped $\mathrm{GaN}$ layers

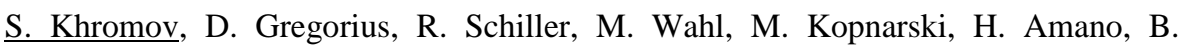
Monemar, L.Hultman, and G. Pozina

Manuscript in final preparation

I planned the study, did TEM and CL, took part in APT characterization, and wrote the paper.

5. Effect of silicon and oxygen doping on donor bound excitons in bulk GaN

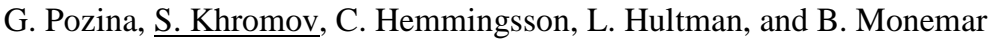
Physical review B 84, 165213 (2011)

I took part in planning, performed TEM characterization, contributed to discussion and to the writing of the paper. 
6. Correlation between $\mathrm{Si}$ doping and stacking fault related luminescence in homoepitaxial m-plane GaN

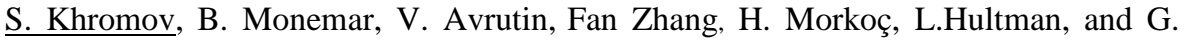
Pozina

Applied Physics Letters 103, 192101 (2013)

I contributed to planning, performed large part of characterization (TEM, CL), and took part in writing of the manuscript.

7. Effect of C-doping on near-band gap luminescence in bulk GaN substrates grown by halide vapor phase epitaxy

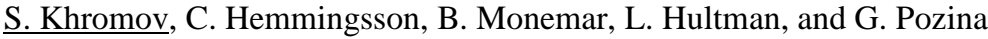

Submitted to Physical Review B

I contributed to planning, performed characterization except for PL, took part in discussion, and wrote the first version of the manuscript. 


\section{RELATED BUT NOT INCLUDED PAPER}

8. Growth of GaN nanotubes by halide vapor phase epitaxy

Carl Hemmingsson, Galia Pozina, Sergey Khromov, and Bo Monemar

Nanotechnology 22 (2011) 085602 


\section{ACKNOWLEDGEMENTS}

I would like to express my gratitude to people who have helped and supported me during my $\mathrm{PhD}$ :

My first supervisor Docent Galia Pozina, for giving me the opportunity to do a $\mathrm{PhD}$ in Linköping, for her guidance and support in life and research, huge help with the experimental work and in writing the papers.

My second supervisor Professor Lars Hultman, for always providing good ideas on how to improve my papers and the thesis.

Professor Bo Monemar, for sharing some of his enormous knowledge of IIInitrides and helping with the interpretation of the experimental data.

Docent Carl Hemmingsson for sharing some of his experience of CVD growth and providing the samples.

Professors Hadis Morkoc and Hiroshi Amano and the members of their groups, for providing the samples.

Colleagues in Germany at IFOS, for providing help with the APT measurments.

Thomas, Inger, Kirstin and Camilla, for technical and administrative help.

All the colleagues at Thin Film, Plasma, and Nanostructured Materials groups.

I have met many wonderful friends during my time in Linköping and would like to thank all of them for making my time here fun and memorable.

A special thanks goes to my family. 


\section{Table of Contents}

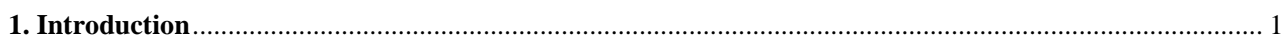

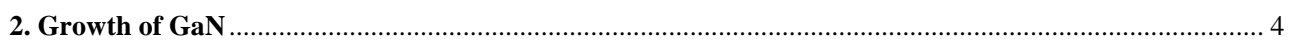

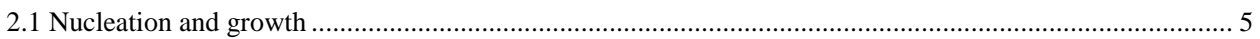

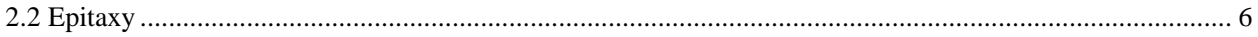

2.3 Basics of a Chemical Vapor Deposition (CVD) process.............................................................. 8

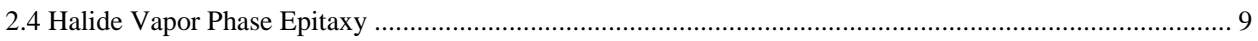

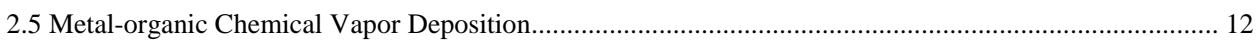

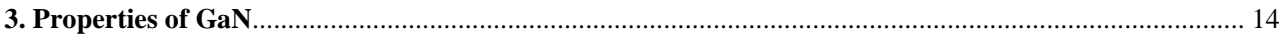

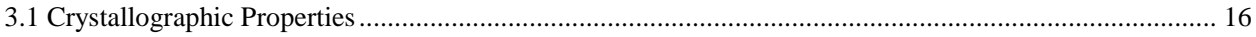

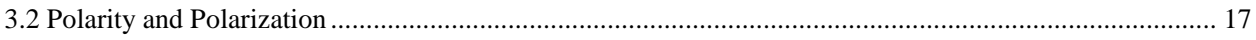

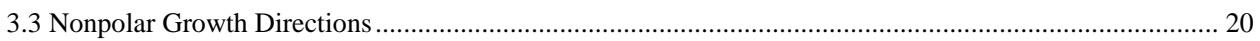

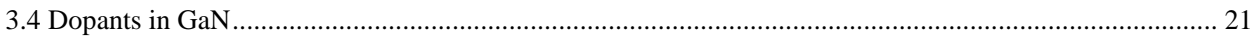

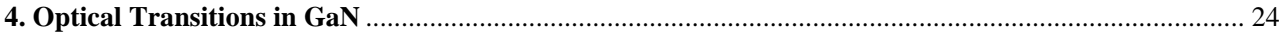

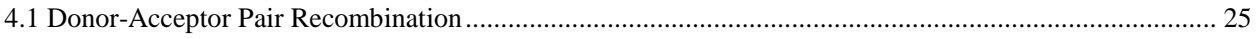

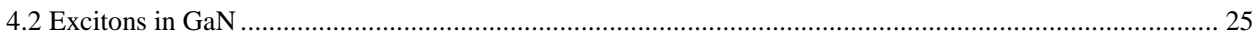

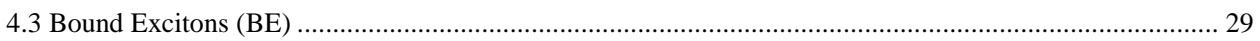

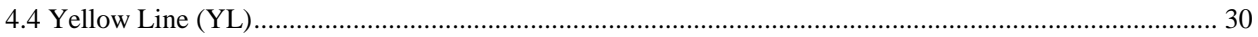

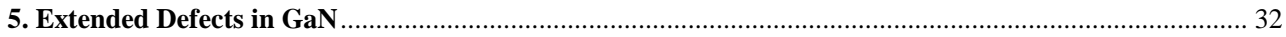

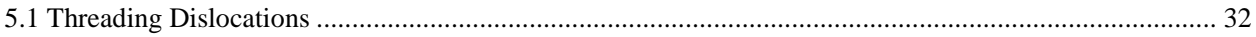

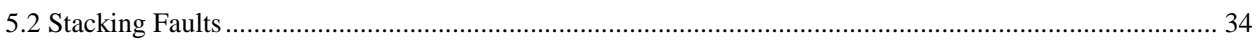

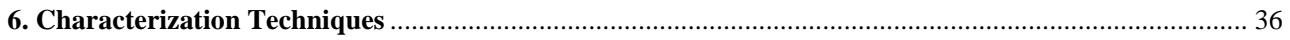

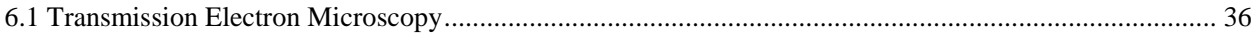

6.2 Scanning TEM and Energy-Dispersive X-ray Spectroscopy …................................................... 38

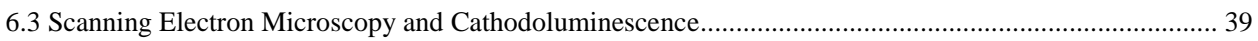

6.4 Photoluminescence and Time-resolved Photoluminescence ................................................................ 43

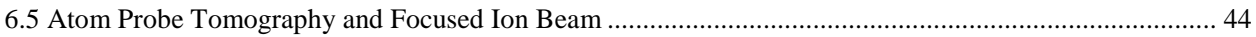

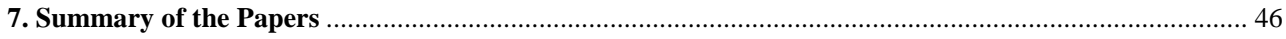

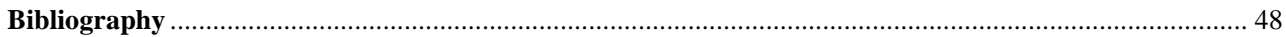




\section{Introduction}

With the invention of light emitting diode (LED) technology and demonstration of the laser diode (LD) in 1960s there began a search for materials that would be suitable to make efficient optoelectronic devices based on these effects. Soon it was understood that II-VI and III-V group materials are appropriate for this goal. III-V semiconductor GaAs and its compounds were used for manufacturing of high efficiency red to yellow LEDs and LDs. To produce high brightness full-color displays or to make high brightness white light sources an efficient blue LED was needed. Possible candidates for short-wavelength LEDs were II-VI compounds like $\mathrm{ZnSe}$ and the indirect bandgap semiconductor SiC. Short lifetimes of ZnSebased devices and low efficiencies of SiC-based LEDs, however, severely limited their use [1]. GaN, on the other hand, looked much more promising for production of short wavelength devices.

$\mathrm{GaN}$ is a III-V group semiconductor with a relatively large direct energy bandgap of $3.4 \mathrm{eV}$. Related compound $\mathrm{AlN}$ has $6.2 \mathrm{eV}$ bandgap and $\mathrm{InN}-0.64 \mathrm{eV}$ (Fig. 1.1). Synthesizing ternary compounds AlGaN, AlInN, and InGaN provides a large flexibility in bandgap engineering: light emitters and detectors working from near infrared to ultraviolet (UV) regions are possible to produce. Multi-junction solar cell approach based on InGaN, for example, offers possibility of using the whole solar energy range with theoretical efficiencies of $60 \%$ [2] compared to theoretical efficiency limit for Si based solar cells at $~ 30 \%$ [3].

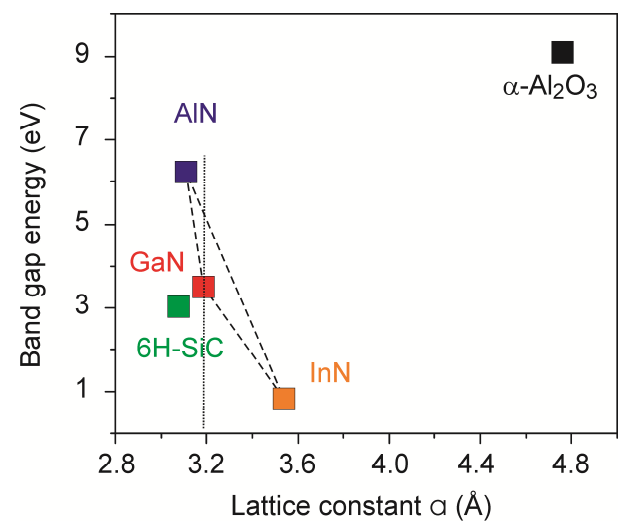

Figure 1.1. Bandgap energies of III-V nitrides as a function of their lattice constants. 
Due to its high vapor pressure of $45000 \mathrm{~atm}$. and high melting point temperature of $2500{ }^{\circ} \mathrm{C}$ [4] it is practically impossible to grow single crystals of $\mathrm{GaN}$ from the liquid phase. Therefore, methods that employ growth from the vapor phase are used to grow GaN, such as molecular-beam epitaxy (MBE), halide vapor phase epitaxy (HVPE) or metal-organic vapor phase epitaxy (MOCVD). The research on GaN started in the early 1970s when the first violet LED based on HVPE-grown GaN was demonstrated by Maruska and Pankove in 1972 [5]. However, further development of GaN-based devices was hindered in the 1970s and 1980s by low crystalline quality and p-type doping issues.

The introduction of a low-temperature buffer layer of AlN on sapphire substrates at the initial growth stages by Amano and Akasaki in 1986 [6] led to a considerable improvement in crystal quality of epitaxial GaN. Later in 1989 the same group solved the $p$ type doping problem. Magnesium was known to be a good $p$-type dopant, nevertheless it was difficult to obtain sufficient hole concentration due to passivation of $\mathrm{Mg}$ atoms by hydrogen, which comes from precursors during the MOCVD growth. Amano and Akasaki proposed low energy electron irradiation as a means to activate charge carriers thus increasing hole concentration to suitable values of $\sim 10^{16} \mathrm{~cm}^{-3}$ [7]. Later thermal annealing in $\mathrm{N}_{2}$ ambient was also suggested to activate the Mg acceptors [8]. As a result of such development Nakamura demonstrated in 1993 the first bright blue and green GaN heterostructure-based LEDs with more than 100 times higher efficiency compared to other alternatives [9].

This breakthrough brought about ever increasing research efforts towards more efficient and brighter blue and white LEDs based on GaN and eventually to a revolution in lighting that we are witnessing right now. Besides solid-state lighting and solar cells, GaNbased devices find applications in full-color LED displays and indicators, data storage (Bluray technology uses GaN-based LDs), telecommunications (optical fiber networks), high power electronics, water purification and many others.

One of the remaining challenges on the way to produce better devices is the lack of native substrates for GaN. Instead, heteroepitaxial growth of $\mathrm{GaN}$ is usually done on sapphire $\left(\alpha-\mathrm{Al}_{2} \mathrm{O}_{3}\right)$ or silicon carbide $(6 \mathrm{H}-\mathrm{SiC})$, for commercial purposes. Growth on foreign substrates leads to a high dislocation density due to a substantial difference in lattice constants (Fig. 1.1) and in thermal expansion coefficients. Threading dislocation density in GaN grown on sapphire is $\sim 10^{8}-10^{9} \mathrm{~cm}^{-2}[10]$ and it is rather surprising that working devices exist with such a high density of defects. Threading dislocations act as nonradiative recombination 
centers [11] and as scattering centers that affect carrier mobility [12], [13]. Other extended defects include stacking faults (SFs) and associated with them partial dislocations. They are typical for nonpolar grown $\mathrm{GaN}$ where the density of SFs and partial dislocations is typically $10^{5} \mathrm{~cm}^{-1}$ and $10^{10} \mathrm{~cm}^{-2}$, respectively [14]. The structural defects have detrimental effects on optoelectronic devices because they increase the current threshold in emitters, cause leakage in the form of dark current in detectors, and lower working lifetimes.

Another challenge is the development of nonpolar grown $\mathrm{GaN}$ and related alloys. High piezo and spontaneous polarization fields present in polar (c-plane oriented) III-N materials cause band bending of the quantum well heterostructures in the active layers leading to nonlinear optical effects and lowered radiative efficiency. Nonpolar ( $m$-plane, $\{1 \overline{1} 00\}$, and $a$ plane, $\{11 \overline{2} 0\}$, oriented) GaN material do not suffer this problem and consequently underwent a considerable development during the last 15 years. Initially, devices based on the nonpolar III-N layers were mostly grown on foreign substrates, e.g., (100) $\gamma$ - $\mathrm{LiAlO}_{2}$ or $r$-plane sapphire. External quantum efficiency of such devices proved to be much lower compared to early nonpolar devices grown on native $m$-plane GaN substrates [15]. Development of nonpolar $\mathrm{GaN}$ grown on native substrates is therefore highly desirable.

$\mathrm{Mg}, \mathrm{C}, \mathrm{Si}$, and $\mathrm{O}$ are the major elements that are used for doping in $\mathrm{GaN}$. $\mathrm{Mg}$ is the only working $p$-type dopant successfully used in III-N optical device fabrication. $\mathrm{C}$ was found to be useful for producing highly resistive semi-insulating back-barrier layers for high electron mobility transistors (HEMT). Si is the main $n$-type doping element and $\mathrm{O}$ is mainly found as a residual n-type dopant. Better understanding of dopants' optical signatures, of, in particular, acceptor bound exciton (ABE) lines in case of $\mathrm{Mg}$, donor bound excitons (DBE) in case of $\mathrm{Si}$ and $\mathrm{O}$, and emissions related to $\mathrm{C}$ would provide ways for improvement of the $\mathrm{GaN}$ material, and consequently more efficient devices.

This thesis is focused on the optical and structural properties of bulk, polar and nonpolar homoepitaxial $\mathrm{GaN}$ doped with $\mathrm{Mg}, \mathrm{C}, \mathrm{Si}$ or $\mathrm{O}$. The appended papers with research results are preceeded by several chapters giving an introduction to the field. Chapter 2 introduces $\mathrm{GaN}$ growth techniques, in Chapter 3 properties of $\mathrm{GaN}$ are given, Chapter 4 treats optical transitions dominating GaN optical spectra, in Chapter 5 nature of extended defects is discussed, characterization techniques used to obtain the results are described in Chapter 6 and, finally, and in Chapter 7 a summary of the papers is given. 


\section{Growth of GaN}

More traditional semiconductors like silicon or gallium arsenide are typically grown from liquid phase by Czochralski or Bridgman methods. GaN, on the other hand, when heated to atmospheric pressure dissociates rather than melts, thus growth from liquid phase at reasonable conditions is impossible. Table 2.1 shows melting temperatures and pressures for several of the most typical semiconductors [16]. For GaN, melting temperature is a theoretically calculated value [4] and melting pressure is an extrapolated value from the experimental data [17]. It can be seen that these values are much bigger compared to common semiconductor materials and rather close to the values of diamond synthesis. Therefore, vapor phase deposition techniques are used for $\mathrm{GaN}$ growth.

Table 2.1. Melting conditions of semiconductors [16].

\begin{tabular}{lll}
\hline Crystal & $\mathbf{T}_{\mathbf{M}},{ }^{\mathbf{0}} \mathbf{C}$ & $\mathbf{p}_{\mathbf{M}}, \mathbf{a t m}$. \\
\hline Si & 1400 & $<1$ \\
GaAs & 1250 & 15 \\
GaP & 1465 & 30 \\
GaN & 2500 & 45000 \\
Diamond & 1600 & 60000 \\
(synthesis) & & \\
\hline
\end{tabular}

There exist three major growth techniques for GaN growth: molecular beam epitaxy (MBE), HVPE, and MOCVD. MBE is a non-equilibrium vapor phase epitaxy growth method, where solid or gas source elements are heated in evaporators, to produce beams of atoms impinging on the substrate, which is rotated and heated to appropriate temperature. Deposition occurs under ultra-high vacuum $\left(10^{-9}\right.$ Torr $)$ conditions, which is the costly drawback of this method. The advantages are the lower, compared to other methods, growth temperatures of $600-800{ }^{\circ} \mathrm{C}$ and possibility to grow very thin layers with fine control of 
composition. Precision of this growth technique is based on low deposition rates and in-situ characterization capabilities. For example, reflection high energy electron diffraction (RHEED) detector allows to control the film thickness up to one atomic layer. Nevertheless this method remains more of a research tool due to quite low growth rates (typically less than $1 \mu \mathrm{m} / \mathrm{h}[18])$ and rather sophisticated equipment.

Thin and thick films of $\mathrm{GaN}$ studied in this thesis were grown by chemical vapor deposition techniques - HVPE and MOCVD - so they will be described in more detail.

\subsection{NUCLEATION AND GROWTH}

During growth from gas-phase on heterogeneous substrates three different growth modes can take place (Fig. 2.1): (1) island (Volmer-Weber) growth occurs when the deposited atoms are more strongly bound to each other than to the substrate; (2) layer-by-layer (Frank-Van der Merwe) growth mode occurs when stronger adatom-substrate bonding leads to planar, layerby-layer deposition; (3) Stranski-Krastanov mode is a combination of the previous two. The latter starts with several complete monolayers and continues with 3D island growth as layerby-layer growth becomes energetically unfavorable. When growing semiconductor materials for electronics and optoelectronics, such as $\mathrm{GaN}$, it is a requirement to obtain single crystal epitaxial films, therefore growth parameters must be adjusted so that layer-by-layer growth takes place.

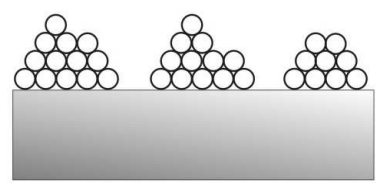

Island (Volmer-Weber) mode

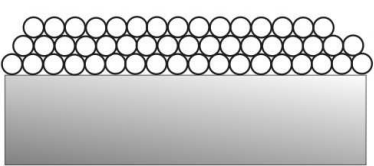

Layer-by-layer

(Frank-Van der Merwe) mode

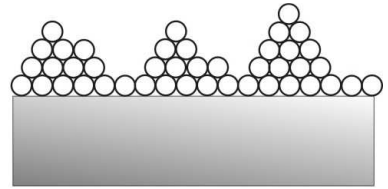

Stranski-Krastanov mode

Fig. 2.1. Three growth modes possible during heteroepitaxy. 


\subsection{EPITAXY}

Epitaxy is a combination of the two Greek words, $\varepsilon \pi \imath$ (epi, meaning "above, upon") and $\tau \alpha \xi_{1} \zeta$ (taxis, meaning "arrangement, order"). It means the formation of a single-crystal film on top of a substrate material, where crystallographic properties of the grown film are largely influenced by the host material. Two types of epitaxy can be distinguished: homoepitaxy and heteroepitaxy. If the substrate and the deposited film are of the same material then this is called homoepitaxy. The most typical example of homoepitaxy is Si on Si. Higher-quality films, lower defect density and doping control are known advantages of homoepitaxy. Rapid development of Si-based early bipolar transistors and integrated circuits was a consequence of adopting epitaxial methods [19].

(a)

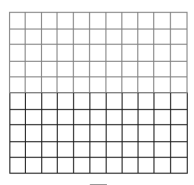

$=$

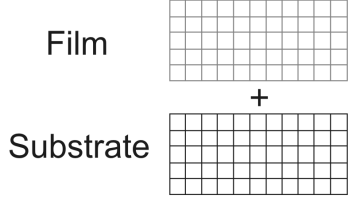

Matched (b)

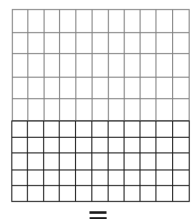

$=$

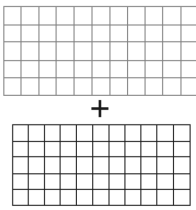

Strained (c)

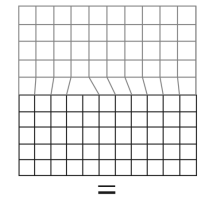

$=$

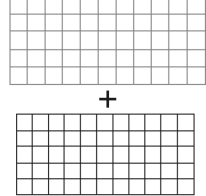

Relaxed

Fig 2.2. Three possible cases of heteroepitaxy: matched, strained, and relaxed [19].

If the deposited material is different (but normally of the same crystal structure) from that of the substrate this is the case of heteroepitaxy. When the lattice parameters of the film and the host material are the same, the sort of heteroepitaxy is called to be matched between lattice planes (see Fig. 2.2, a). In most cases lattice parameters of the two materials are different, therefore in heteroepitaxy interfacial bond straining arises between the film and the substrate (Fig. 2.2, b). The film grows in a strained state up to a certain, so called critical thickness, after which the accumulated strain is released either elastically by $3 \mathrm{D}$ island formation - 
Stranski-Krastanov growth - or plastically by formation of misfit dislocations - Frank-Van der Merwe growth (Fig. 2.2, c) [20].

Due to lack of native substrates mentioned above, $\mathrm{GaN}$ is still predominantly grown heteroepitaxially on $\mathrm{SiC}(3.5 \%$ lattice mismatch) or sapphire (16.09\% lattice mismatch). Table 2.2 gives a comparison of $\mathrm{GaN}$ lattice and bandgap with those of potential substrate materials. Large lattice mismatch and difference in thermal expansion coefficients between the film and the substrate materials results in high density of misfit dislocations, which lie in the film/substrate interface plane. A different type of dislocations that is reported to be detrimental for electrical and optical propreties of $\mathrm{GaN}$ devices is threading dislocations (TDs) [21]. TDs propagate perpendicular to the film/substrate interface. Their origin is, however, controversial, as discussed in Chapter 4.

Table 2.2. Lattice properties and bandgaps of $\mathrm{GaN}$ and potential substrate materials [22].

\begin{tabular}{|c|c|c|c|c|c|}
\hline $\begin{array}{l}\text { Material } \\
\text { (crystal } \\
\text { symmetry) }\end{array}$ & $\begin{array}{l}\text { Lattice } \\
\text { constants, } \AA\end{array}$ & $\begin{array}{l}\text { Plane with } \\
\text { closest match to } \\
(0001) \mathrm{GaN}\end{array}$ & $\begin{array}{l}\text { Effective a } \\
\text { lattice constant, } \\
\AA\end{array}$ & $\begin{array}{l}\text { Lattice mismatch } \\
\text { with } \mathrm{GaN}(\%) \\
\left(\mathrm{a}_{\mathrm{GaN}}-\mathrm{a}_{\mathrm{sub}}\right) / \mathrm{a}_{\mathrm{sub}}\end{array}$ & Bandgap, eV \\
\hline $\begin{array}{l}\text { GaN } \\
\text { (hexagonal) }\end{array}$ & $\begin{array}{l}\mathrm{a}=3.1891 \\
\mathrm{c}=5.1855\end{array}$ & $(0001)$ & 3.1891 & 0 & 3.44 \\
\hline $\mathrm{Al}_{2} \mathrm{O}_{3}$ (trigonal) & $\begin{array}{l}\mathrm{a}=4.758 \\
\mathrm{c}=12.991\end{array}$ & $\begin{array}{l}(0001), \text { rotated } \\
30^{\circ}\end{array}$ & 2.747 & 16.09 & $>8.5$ \\
\hline $\begin{array}{l}\mathrm{H}-\mathrm{SiC} \\
\text { (hexagonal) }\end{array}$ & $\begin{array}{l}\mathrm{a}=3.073 \\
\mathrm{c}=10.053\end{array}$ & $(0001)$ & 3.073 & 3.77 & 3.2 \\
\hline $\begin{array}{l}\text { 6H-SiC } \\
\text { (hexagonal) }\end{array}$ & $\begin{array}{l}\mathrm{a}=3.081 \\
\mathrm{c}=15.117\end{array}$ & $(0001)$ & 3.081 & 3.51 & 2.86 \\
\hline
\end{tabular}

As was mentioned in Chapter 1, the introduction of low temperature AlN or $\mathrm{GaN}$ buffer layers lead to the dramatic improvement in GaN epitaxial films' quality. Adoption of low temperature buffer layer techniques allowed 2D Frank-Van der Merwe growth mode to be obtained. At the same time development and industrial application of bulk GaN layers that can be used as native substrates promises even higher light output due to lower number of intrinsic defects, e.g. TDs, that act as non-radiative centers. By using native substrates TDs density, for example, can be lowered to $\sim 10^{6} \mathrm{~cm}^{-2}$ compared to $\sim 10^{9} \mathrm{~cm}^{-2}$ for growth on foreign substrates [23]. 


\subsection{BASICS OF A CHEMICAL VAPOR DEPOSITION (CVD)}

\section{PROCESS}

Unlike in physical vapor deposition (PVD) methods where atom species are just deposited on the substrate, in CVD atoms and molecules that are transported to the substrate undergo chemical reactions and thereby form the film. HVPE and MOCVD techniques can be differentiated based on which Ga precursors are used - organic or inorganic. CVD methods allow higher purification of precursors compared, for example, to solid sources used in PVD techniques, which is extremely important due to the necessity of precise dopant control as dopants define electrical and optical properties of semiconductor material.

CVD processes typically includes the following steps for the film growth to occur (Fig. 2.3):

1. Transport of precursors to the reaction zone

2. Chemical reactions of precursors to produce reactive species and by-products

3. Diffusion of the reactants and their products to the substrate surface

4. Physical and chemical adsorption of the reactants on the crystal surface

5. Diffusion and incorporation of the species

6. Desorption and transport of the reaction by-products away from the reaction chamber.

Part of this thesis is focused on HVPE grown bulk GaN (Papers 5 and 7), while another section deals with polar and non-polar GaN films grown by MOCVD homoepitaxially on HVPE substrates (Papers 1-4 and 6). 


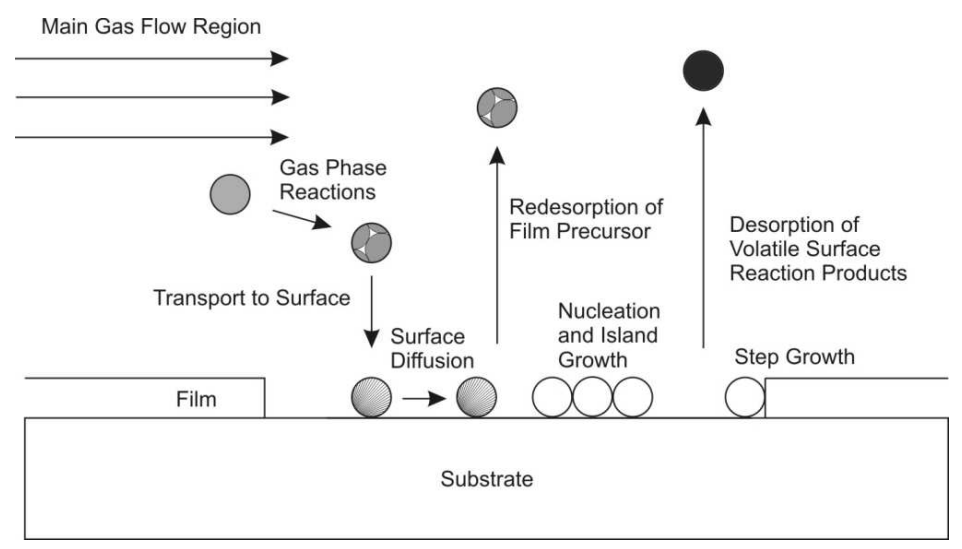

Fig. 2.3. Gas transport and reactions during a typical CVD process [24].

\subsection{HALIDE VAPOR PHASE EPITAXY}

HVPE dominated as a growth method during the early stages of GaN research [25]. Due to difficulties in obtaining p-type conductivity (by doping with $\mathrm{Zn}$ or $\mathrm{Mg}$ ) and poor crystallinity by HVPE attention shifted to MOCVD technique in the 1980s. In recent years HVPE method gained popularity again for the growth of thick GaN layers for substrate applications. This is driven by the development of blue LEDs for high density storage, high brightness LEDs and power devices that need a native substrate to fully realize the potential of the III-nitride materials system [26]. Compared to other III-V material systems progress in bulk GaN lies significantly behind the epitaxial film development. The cost of GaN commercially available substrates is around $100 \$ / \mathrm{cm}^{2}$ compared to less than $1 \$ / \mathrm{cm}^{2}$ for GaAs [27].

The reasons HVPE is considered advantageous for substrate growth are its inherent high growth rates (up to $300 \mu \mathrm{m} / \mathrm{h}$ ), relatively easy and well understood chemistry, possibility of easily scaling up the process and low cost. Films grown with HVPE are also virtually free from carbon due to the absence of carbon species in the growth process (compared to MOCVD). Challenges faced by HVPE method are that the films can be of nonuniform quality, they can exhibit domain structure as well as bowing and cracking due to lattice mismatch and thermal coefficient difference between sapphire and $\mathrm{GaN}$. 
Thick HVPE GaN films for Papers 1, 5, and 7 were grown by Carl Hemmingsson at $\mathrm{LiU}$ in a vertical hot wall HVPE reactor. It is schematically depicted in Fig. 2.4. The chamber is made of quartz and is heated resistively and by RF induction. There are two temperature zones: the metallic source zone, which is heated resistively, is kept at the temperature of $\sim 800-900{ }^{\circ} \mathrm{C}$, whereas the growth zone, which is heated by RF induction, is at $\sim 1000-1100$ ${ }^{\circ} \mathrm{C}$.

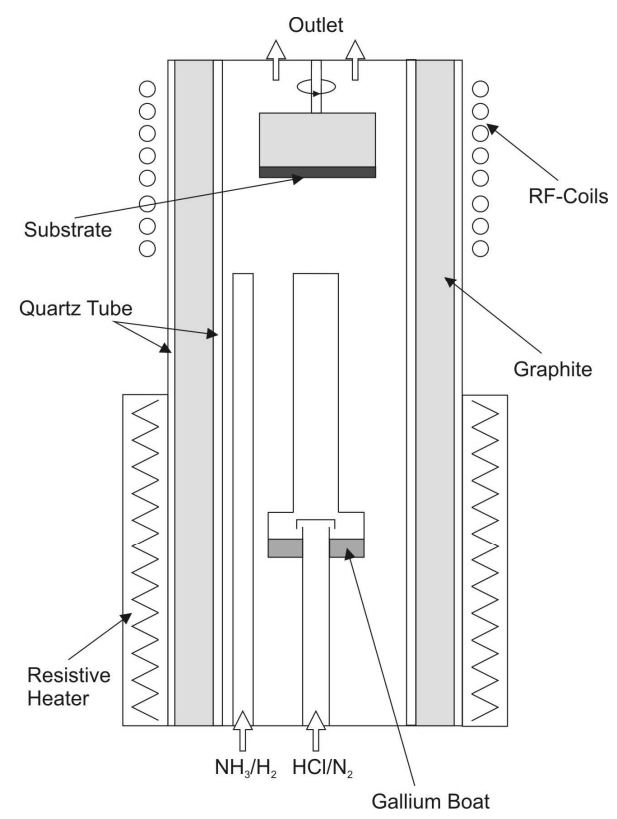

Fig. 2.4. Schematic drawing of a HVPE GaN growth reactor [28].

Hydrogen chloride is let into the quartz tube with molten Ga where reaction producing gaseous gallium monochloride occurs:

$$
2 \mathrm{Ga}+2 \mathrm{HCl} \rightarrow 2 \mathrm{GaCl}+\mathrm{H}_{2}
$$

The efficiency of this process is very high, above 95\% [29]. In a separate tube $\mathrm{NH}_{3}$, the group V source, is flowed. Subsequently ammonia and gallium chloride undergo the following reaction on the surface of the substrate:

$$
\mathrm{GaCl}+\mathrm{NH}_{3} \rightarrow \mathrm{GaN}+\mathrm{HCl}+\mathrm{H}_{2}
$$


The growth process is conducted under ammonia rich conditions, normally $\mathrm{NH}_{3}$ to $\mathrm{HCl}$ flow ratio is $25-30$.
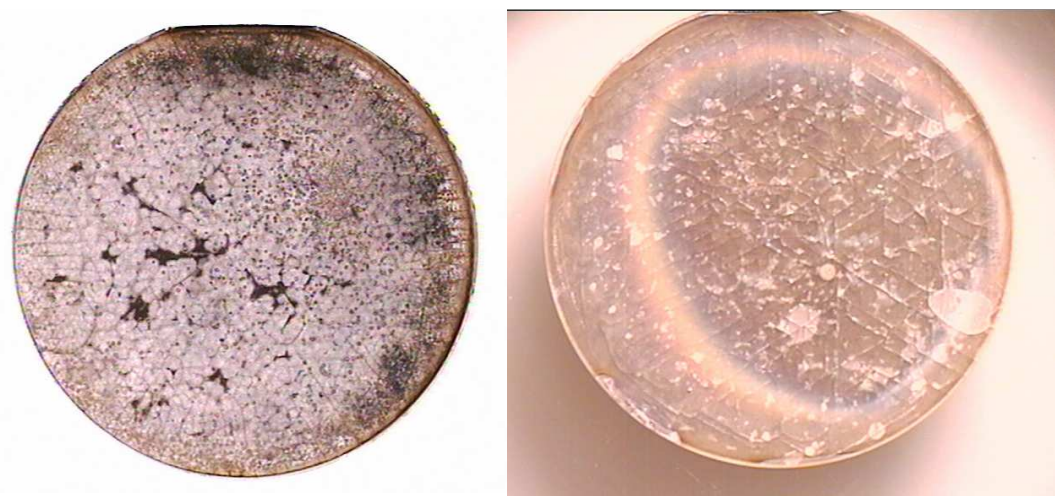

Fig. 2.5. Light microscopy image of C-doped bulk (> $2 \mathrm{~mm}$ ) GaN samples from Paper 7, front GaN side (a) and back sapphire side (b).

To prevent parasitic growth in the gas inlet ammonia and halide $(\mathrm{GaCl})$ should not be mixed before they reach the substrate. Light molecule gases such as $\mathrm{H}_{2}$ or mixtures of $\mathrm{N}_{2}$ and $\mathrm{H}_{2}$ are used as carrier gases to obtain laminar flow. The deposition rate is very high compared to other methods, $\sim 100-300 \mu \mathrm{m}$. The process is operated at atmospheric pressure, at near equilibrium conditions and is mass transport limited by the flow of halide precursor.

For C-doping in Paper 7 acetylene gas $\left(\mathrm{C}_{2} \mathrm{H}_{2}\right)$ diluted in $\mathrm{N}_{2}$ was used. In Paper 5 Odoping was achieved by flowing $\mathrm{O}_{2}$ mixed with $\mathrm{N}_{2}$ and $\mathrm{Si}$-doping by flowing silane $\left(\mathrm{SiH}_{4}\right)$ mixed with $\mathrm{H}_{2}$. A light microscopy image of C-doped bulk (>2 $\mathrm{mm}$ ) GaN samples from Paper 7, front GaN side and back sapphire side, are demonstrated in Fig. 2.5 (a) and (b). A combination of HVPE and MOCVD techniques can yield higher quality GaN substrates. Therefore, growth of thick HVPE layers studied in this thesis was always done on a thin (2-3 $\mu \mathrm{m})$ MOCVD GaN layers grown on sapphire, the so-called template. 


\subsection{METAL-ORGANIC CHEMICAL VAPOR DEPOSITION}

The first time MOCVD was used to grow III-V materials was the growth of GaAs by Manasevit in 1968 [30]. Application of MOCVD to the growth of GaN and AlN was demonstrated by Manasevit et al in 1971 [31], however, due to low purity of precursors and non-optimized processes no semiconductor-quality GaN was obtained. Real breakthrough with the MOCVD growth of GaN was achieved in 1986 by Amano and Akasaki [6] when, now widely used, "two step method" technique was implemented. During "two step method" growth a thin (several tens of nm), low temperature heteroepitaxial GaN or AlN buffer layer is introduced on sapphire and, only upon that, a high temperature GaN film is grown. Low temperature buffer layers play a role as nucleation layer, which absorbs strain formed during heteroepitaxila growth. Solution of the p-type problem [7] and demonstration of the first blue LED [32] contributed to the success of MOCVD. Nowadays it is by far the most commercially used method for III-nitride growth.

In MOCVD, in contrast to HVPE, instead of inorganic species metal-organic precursors are flown in the reactor as sources of $\mathrm{Ga}$. Specifically trimethylgallium $\left(\left(\mathrm{CH}_{3}\right)_{3} \mathrm{Ga}\right)$ is used as $\mathrm{Ga}$, and ammonia - as nitrogen precursors. For Mg doping, organic compounds are used too, specifically for samples in Paper 1-4 bis-cyclopentadienylmagnesium (Cp2Mg) was employed. Alternatively, silane ( $\mathrm{SiH} 4)$ was used as a source for $\mathrm{Si}$ (n-type) doping of GaN (Paper 6). Organic species and ammonia are transported in separate pipes to the quartz chamber in order to prevent premature reacting. Lighter carrier gases $\left(\mathrm{H}_{2}\right.$ or $\left.\mathrm{N}_{2}\right)$ are let through organic compound liquids thus transporting the precursors to the reactor. These compounds are thermally dissociated over the surface of $\sim 1000{ }^{\circ} \mathrm{C}$ hot substrate and react in a sequence of complex reactions forming GaN. In hot wall MOCVD the whole reactor is heated by RF coils, whereas in the cold-wall process only the susceptor, which is usually made of graphite, is heated. The substrate may be rotated to obtain uniform films. Before the growth is started nitridation of the substrate is usually done to reduce lattice mismatch due to the nitrides formed on the substrate surface ( $\mathrm{SiN}$ on $\mathrm{SiC}$ or $\mathrm{AlN}$ on $\mathrm{Al}_{2} \mathrm{O}_{3}$ ). The usual practice, and how it was done for the growth of the samples studied in this thesis, is to start epitaxial growth on sapphire substrates with a low-temperature $\left(\sim 600^{\circ} \mathrm{C}\right) \mathrm{GaN}$ buffer layer ("two step method"). 
Ease of scalability, high uniformity, and quality of the films as well as a relatively high growth rates $(\sim 1 \mu \mathrm{m} / \mathrm{h})$ are making this technique the method of choice for commercial purposes. Undoped 0.5- $\mu \mathrm{m}$-thick buffer layer and 1- $\mu \mathrm{m}$-thick Mg-doped epitaxial layer for samples in Paper 1, 4 were grown by MOCVD. In Paper $2400 \mathrm{~nm}$ Mg-doped layer, starting with an undoped $0.6 \mu \mathrm{m} \mathrm{GaN}$ layer, and in Paper 6 1- $\mu \mathrm{m}$-thick Si doped m-plane GaN layers were grown by this method as well.

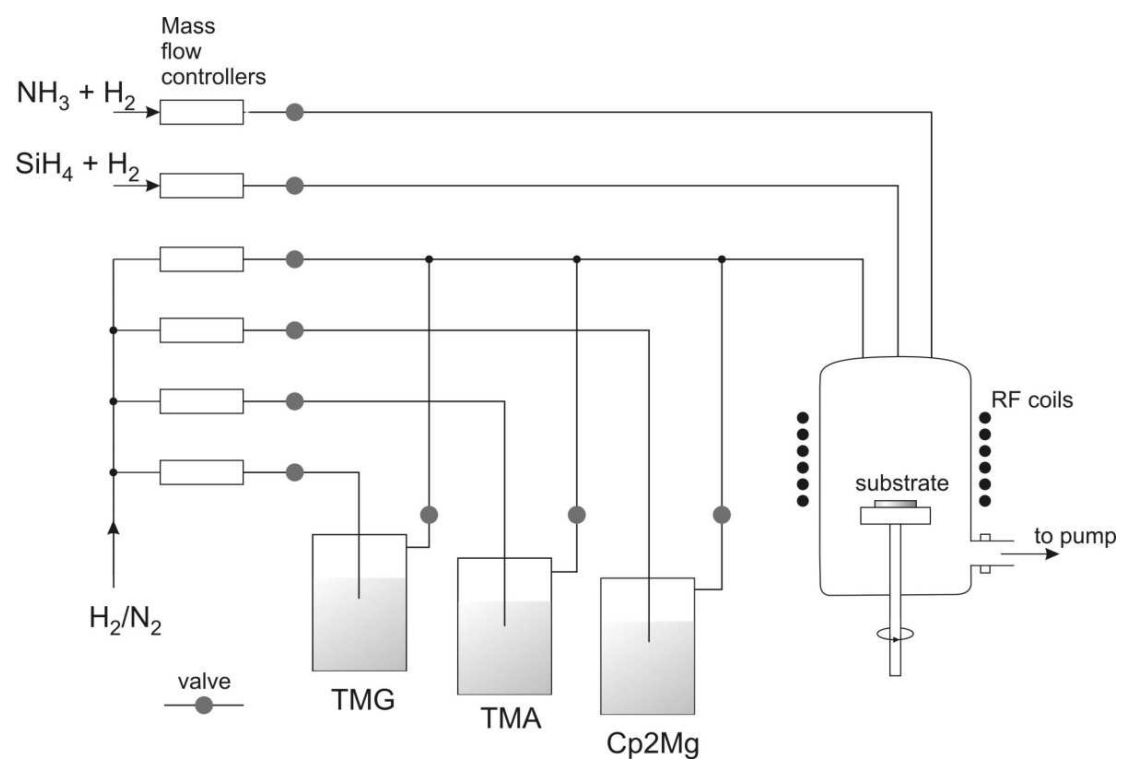

Fig. 2.6. Schematic drawing of a MOCVD reactor that was used for growth of GaN epilayers. TMG stands for trimethylgallium, TMA - for trimethylalluminium and $\mathrm{Cp} 2 \mathrm{Mg}$ - for biscyclopentadienylmagnesium. 


\section{Properties of GaN}

Atomic bonds in III-V semiconductors are covalent with some degree of ionicity. Compared to other group V-elements, nitrogen has a smaller atomic radius and a lower Coulomb screening due to a smaller number of electrons, meaning that the electrons are tightly bound. This makes $\mathrm{N}$ a very electronegative element bringing a much higher degree of ionicity to the III-N bond. According to Pauling ionicity criteria GaN has 0.387 ionicity compared to 0.039 for GaAs. This high ionicity leads to a stronger bond strength and a shorter bond length, which in turn, explain some of the macroscopic physical properties of GaN, such as significant hardness and chemical stability. Other superior material properties of $\mathrm{GaN}$ are high electron mobility, high thermal conductivity, high critical field and direct wide bandgap. These properties are presented and compared to the properties of other major semiconductors in Table 3.1.

Table 3.1. Important properties of GaN at $300 \mathrm{~K}$ [33]-[35], [36].

\begin{tabular}{|l|l|l|l|l|l|}
\hline Material & Bandgaps, $\mathrm{eV}$ & $\begin{array}{l}\text { Lattice } \\
\text { constants, } \mathrm{A}\end{array}$ & $\begin{array}{l}\text { Mobility, } \mathrm{cm}^{2} \cdot \mathrm{V}^{-1} \cdot \mathrm{s}^{-} \\
1\end{array}$ & $\begin{array}{l}\text { Thermal } \\
\text { conductivity, } \\
\mathrm{W} \cdot \mathrm{cm}^{-1} \mathrm{C}^{-1}\end{array}$ & $\begin{array}{l}\text { Breakdown } \\
\text { field, } \\
\mathrm{V} \cdot \mathrm{cm}^{-1}\end{array}$ \\
\hline $\mathrm{GaN}$ & $\begin{array}{l}3.4 \\
\text { direct }\end{array}$ & $\begin{array}{l}\mathrm{a}=3.189 \\
\mathrm{c}=5.186\end{array}$ & $\begin{array}{l}\text { electrons } 1000 \\
\text { holes } 200\end{array}$ & 1.5 & $>5 \times 10^{6}$ \\
\hline $\mathrm{Si}$ & $\begin{array}{l}1.1 \\
\text { indirect }\end{array}$ & $\begin{array}{l}5.431 \\
\mathrm{GaAs}\end{array}$ & $\begin{array}{l}\text { electrons } 1400 \\
\text { holes } 450\end{array}$ & 1.5 & $3 \times 10^{5}$ \\
\hline $6 \mathrm{H}-\mathrm{SiC}$ & $\begin{array}{l}2.9 \\
\text { indirect }\end{array}$ & $\begin{array}{l}\mathrm{a}=3.073 \\
\mathrm{c}=10.053\end{array}$ & $\begin{array}{l}\text { electrons } 8500 \\
\text { holes } 400\end{array}$ & 0.5 & $4 \times 10^{5}$ \\
holes 40 & $5 \times 10^{6}$ & \\
\hline
\end{tabular}

Direct bandgap is an extremely important property for a material aimed to be used in optoelectronics. Direct bandgap means that the minimum of the conduction band and the maximum of the valence band are aligned in the reciprocal space. Indirect bandgap, on the other hand, means that they are separated by some $\Delta k$ value. Schematic examples of direct 
and indirect bandgaps are presented in Fig. 3.1. During the operation of an optoelectronic device holes and electrons are injected into the p-n junction. To efficiently recombine and produce photons they should be at the same position in the reciprocal space. In indirect bandgap materials a hole and an electron are separated and recombination can occur only by emitting or absorbing a phonon that would compensate $\Delta k$ difference. This process is, however, orders of magnitude less probable than the recombination process in a direct bandgap material.

Therefore, mainly direct bandgap semiconductors are suitable for the production of highly efficient optoelectronic devices. Even though $6 \mathrm{H}-\mathrm{SiC}$ has similar bandgap value to $\mathrm{GaN}$ and advantageous properties such as thermal stability and high breakdown field, indirect bandgap was one of the reasons that it was largely discarded in favor of $\mathrm{GaN}$ for the production of blue LEDs.
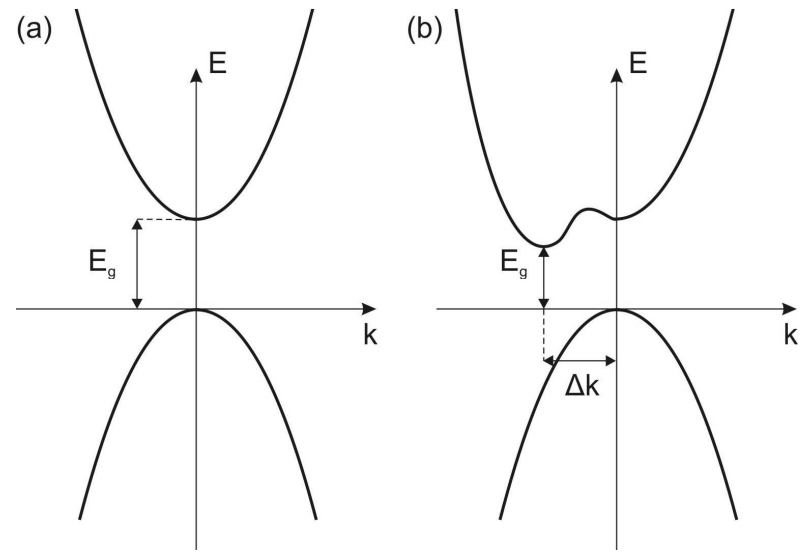

Fig. 3.1. Schematic pictures of (a) direct and (b) indirect bandgaps in semiconductors.

High breakdown field, a consequence of the large energy bandgap, allows higher voltages to be applied to GaN based devices. High charge carrier mobilities offer possibilities of high frequency applications to be realized. High thermal conductivity is beneficial in case of high working temperatures and where fast and efficient heat dissipation is required. These are the reasons to use GaN for making next generation high power/high frequency microwave devices. 


\subsection{CRYSTAllographic PROPERTIES}

$\mathrm{GaN}$ atomic bonds are $s p^{3}$-hybridized which dictates tetrahedral coordination of the atoms, i.e. each $\mathrm{Ga}$ atom is surrounded by four $\mathrm{N}$ atoms and vice versa. GaN has two polytypes where atoms are tetrahedrally coordinated: a cubic, zinc blende phase (space group $F \underline{4} 3 \mathrm{~m}$ ) and a wurtzite, hexagonal phase (space group $P 6_{3} m$ ). Cubic form of GaN is only metastable and difficult to grow, most of the research is therefore focused on wurtzite GaN. All the results in this thesis are also solely obtained from wurtzite GaN. The wurtzite crystal structure can be imagined as two interpenetrating hexagonal closed packed (hcp) lattices, consisting of the corresponding element atoms, Fig. 3.2.

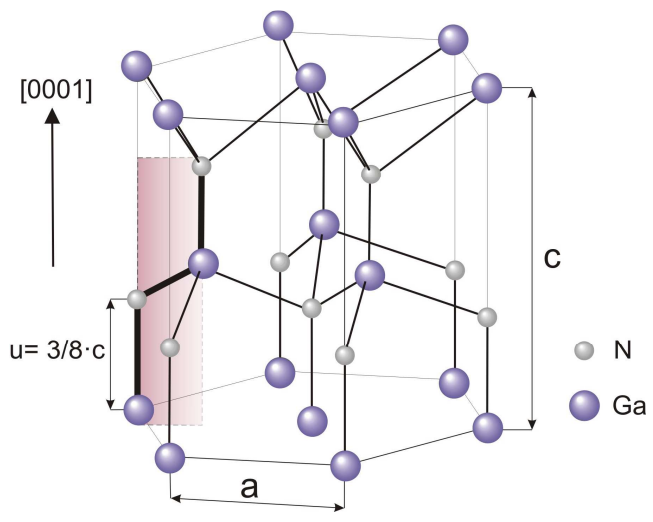

Fig. 3.2. Unit cell of wurtzite GaN. The four basis atoms are highlighted.

The basis (highlighted in Fig. 3.2) consists of four atoms, two of each type, their coordinates are the following: $\mathrm{Ga}$ atom $(0,0,0),(1 / 3,2 / 3,1 / 2)$ and $\mathrm{N}$ atom $(0,0, u),(1 / 3,2 / 3$, $1 / 2+u)$, where $u$ is the distance between $\mathrm{Ga}$ and $\mathrm{N}$ atoms in [0001] direction and it is equal to $3 / 8$ of the unit cell constant $c$. The value $3 / 8 \cdot c$ is only valid for an ideal wurtzite structure, however, and it varies slightly with the degree of non-ideality of the crystal. For GaN, the value of $u$ is 0.376 in unstrained material. There are two different positions for atoms in the wurtzite structure, therefore the stacking sequence can be written as $A a B b A a$, where capital letters denote $\mathrm{Ga}$ atoms and small ones $-\mathrm{N}$ atoms. It is interesting to compare stacking sequences of zinc blende and wurtzite structures, Fig. 3.3, because it can help understand how 
SFs are formed, for example. Zinc blende structure, in difference to wurtzite, consists of three alternating bilayers of atoms: $A a B b C c$.

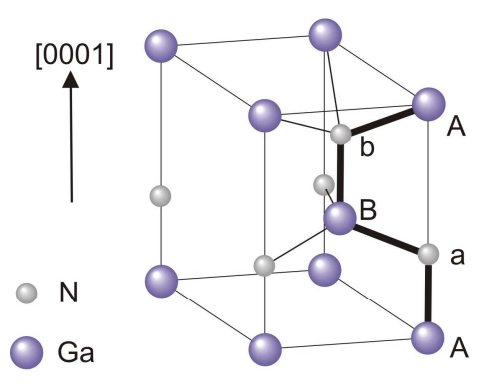

Wurtzite

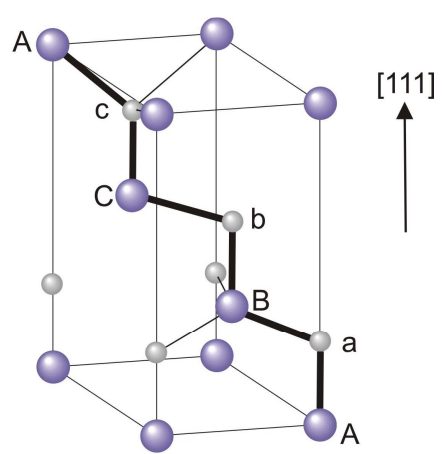

Zinc blende

Figure 3.3. Stacking sequences of wurtzite and zinc blende GaN.

\subsection{POLARITY AND POLARIZATION}

GaN lacks inversion symmetry in the [0001] direction in wurtzite. This means that [0001] and $[000 \overline{1}]$ directions are not equivalent: if we flip the crystal in this direction Ga atoms will end up in $\mathrm{N}$ atom's places and $\mathrm{N}$ atoms - in Ga atom's places. Thus GaN can be grown in two different orientations in [0001] direction: Ga-faced GaN with [0001] orientation and $\mathrm{N}$-faced $\mathrm{GaN}$ with $\left[0001^{-}\right]$orientation. It is important to point out here that Ga-face does not mean that the surface is terminated by Ga atoms (Fig. 3.4). For example, N-face surface can be terminated by $\mathrm{Ga}$ atoms. Instead, polarity is defined by the direction of the Ga-N bond. In this Thesis, I have been concerned primarily with Ga-face GaN layers. 

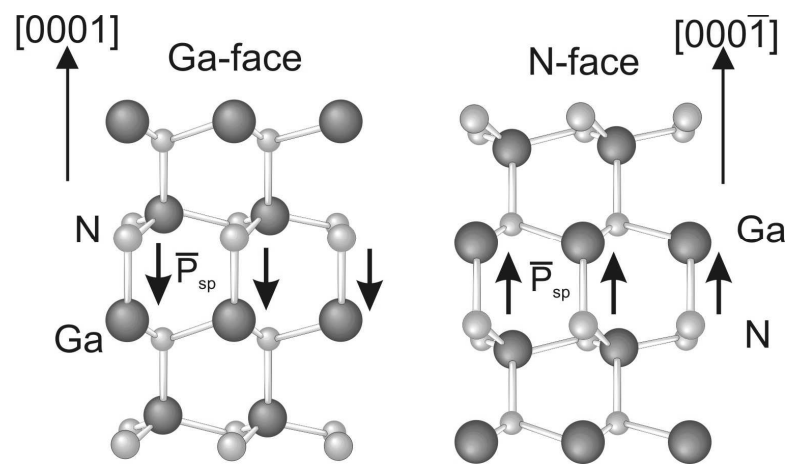

Fig. 3.4. The two different orientations and spontaneous polarization vector in $\mathrm{GaN}$.

High ionicity of the Ga-N bond means that the bonds act like microscopic dipoles. This, in combination with lack of inversion symmetry results in the presence of macroscopic spontaneous polarization in [0001] direction. The word "spontaneous" means that it is present in the absence of strain.

There are 4 bonds pointing in different directions in a GaN tetrahedron. Therefore, the polarization contributed by the vertical bond is counteracted by the polarization contributed by the other three bonds, minimizing the overall spontaneous polarization effect. The degree of minimization is dependent on the angle between the bonds, which in turn, depends on the degree of non-ideality of the crystal, i.e. on deviation of $u$ value from $3 / 8 \cdot c$ and $c / a$ from $c_{0} / a_{0}$. The degrees of non-ideality and its influence on the spontaneous polarization in $\mathrm{GaN}, \mathrm{AlN}$, and $\mathrm{InN}$ are summarized in Table 3.2 for comparison.

Table 3.2. Lattice parameters deviation from the ideal wurtzite structure and its influence on the spontaneous polarization in III-nitrides [37].

\begin{tabular}{|l|l|l|l|l|}
\hline Material & ideal & GaN & AlN & InN \\
\hline$u_{0}$ & 0.375 & 0.376 & 0.380 & 0.377 \\
\hline$c_{0} / a_{0}$ & 1.633 & 1.6336 & 1.6190 & 1.6270 \\
\hline$P_{s p}$ & - & -0.029 & -0.081 & -0.032 \\
\hline
\end{tabular}


Presence of external stress due to lattice mismatch in the films grown on foreign substrates, or in heterostructures, results in additional, piezoelectric contribution to the polarization. The total polarization, therefore, can be presented as the sum of the two components:

$$
\overrightarrow{\mathrm{P}}_{\text {tot }}=\overrightarrow{\mathrm{P}}_{\text {spon }}+\overrightarrow{\mathrm{P}}_{\text {piezo }}
$$

The direction of piezoelectric polarization is dependent on the type of stress that is present. In $\mathrm{AlGaN}$, which has a smaller lattice constant, when it is grown on $\mathrm{GaN}$, the resulting stress is tensile. In InGaN grown on $\mathrm{GaN}$, conversely, the strain is compressive due to a larger than in $\mathrm{GaN}$ lattice constant. The resulting piezoelectric field in these materials has different signs: it is parallel with spontaneous polarization in $\mathrm{AlGaN}$ and antiparallel with it in InGaN. The overall polarization effect in $\mathrm{InGaN}$ is therefore smaller compared to AlGaN.

The polarization fields have very important implications for GaN LED devices. These devices are based on quantum well $(\mathrm{QW})$ heterostructures, where thin layers of material with a narrower bangap are embedded in a wider bandgap material matrix, for example InGaN QW in $\mathrm{GaN}$ matrix or GaN QW in AlGaN matrix. QW structures confine the charge carriers and dramatically increase the probability of their radiative recombination. The presence of spontaneous and piezoelectric polarization in QW leads to bending of the bandgap therefore spatially separating the charge carriers (Fig. 3.5).

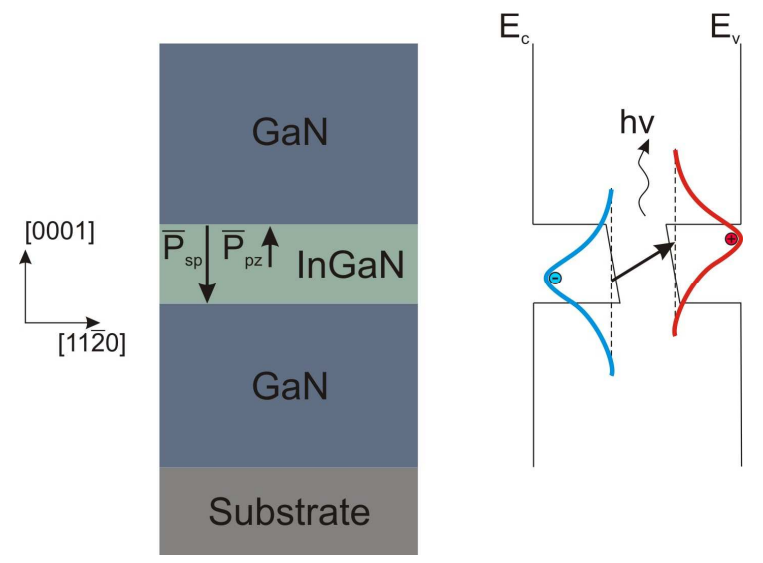

Figure 3.5. Energy band bending in InGaN/GaN QW structure. 
Spatial separation of the charge carriers results in a smaller overlap of the wave functions and consequently in lower recombination probability. Additionally, it red-shifts the output emission, i.e. the emitted photons are of lower energy [38]. This phenomena is called quantum confined Stark effect and is detrimental for optoelectronic devices as it lowers the overall efficiency.

Besides that, tilting of the band edges of the active layer makes the effective width of QWs smaller, which results in higher density of charge carriers and increases probability of non-radiative Auger recombination. Band bending also lowers an effective barrier height in QWs leading to carrier leakage with increasing bias voltage. These two phenomena are believed to cause the so-called "efficiency droop" effect in GaN based light emitters when external quantum efficiency of devices drops with increasing current [39], [40].

While unwanted in optoelectronic devices, built-in electric fields were found to be beneficial for high electron mobility transistors (HEMT), which employ AlGaN/GaN heterojunctions. Polarization field, which is higher in $\mathrm{AlGaN}$ than in $\mathrm{GaN}$ creates a sheet charge at the $\mathrm{AlGaN} / \mathrm{GaN}$ interface. This charge is compensated by the mobile electrons from $n$-type doped AlGaN that diffuse into QW at the interface and end up in semi-insulating $\mathrm{GaN}$ forming the so-called 2-dimensional electron gas (due to confinement in one direction). Ionized impurity atoms from $n$-type dopants in $\mathrm{AlGaN}$ and electrons in the $\mathrm{QW}$ are therefore spatially separated. This eliminates the impurity scattering bringing much higher carrier mobilities.

\subsection{NONPOLAR GROWTH DiRECTIONS}

To solve the problem of high polarization fields present in $c$-plane GaN-based heterostructures, growth on nonpolar planes was proposed [41]. Due to inversion symmetry, polarization fields are compensated in these directions, hence the name nonpolar. There are two nonpolar sets of planes: $a$-planes, $\{11 \overline{2} 0\}$, and $m$-planes, $\{10 \overline{10}\}$, Fig. 3.6. 


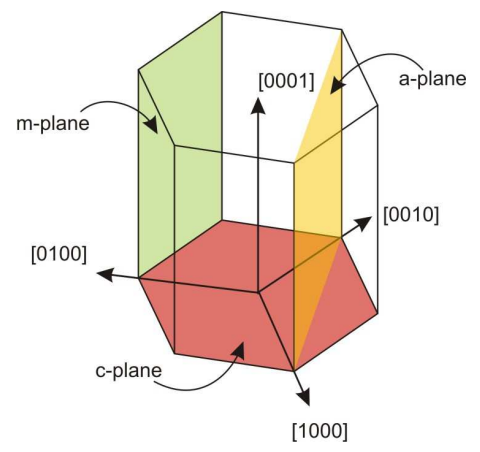

Figure 3.6. Polar (c-) and nonpolar ( $m$ - and $a$-) planes in GaN.

A seminal paper was published by Waltereit et al. [42] in 2000, where nonpolar $m$ plane heterostructures of $\mathrm{GaN} / \mathrm{AlGaN}$ grown on tetragonal $\mathrm{LiAlO}_{2}$ were reported. After this publication interest to nonpolar GaN significantly increased and working devices based on $m$ plane GaN were produced recently [43]-[45].

Heteroepitaxially grown nonpolar GaN layers are known to exhibit poor surface morphology, with striations and pits [46], [47]. Higher concentration of extended defects compared to $c$-plane films, especially SFs, is also a problem of nonpolar GaN. Nonpolar films with improved morphology and microstructure can be obtained if they are grown on native GaN substrates [48]. At the moment nonpolar GaN substrates are prepared simply by cutting the $c$-plane oriented thick HVPE grown GaN substrates along nonpolar direction. In this way small, typically $5 \times 10 \mathrm{~mm}$, nonpolar substrates can be obtained. Due to the small size their availability is still limited and the price is high. $m$-plane homoepitaxially grown GaN layers doped with Mg and Si were investigated in Papers 2 and 6 of this thesis, respectively.

\subsection{DOPANTS IN GAN}

There are two types of dopants in semiconductors: donors and acceptors. Donors are atoms of a chemical element that have more electrons in the outer electron shell than atoms of the host material, whereas acceptors are atoms of an element with lower number of electrons in the outer shell. Thus, donor atoms can provide an excessive electron to the material and acceptors can provide an excessive hole. One of the most important requirements for donor or acceptor 
atoms is that they should introduce sufficiently shallow energy levels in the bandgap to be able to provide a reasonable number of electrons and holes into the material at room temperature. Other factors that determine if an element can be used as a dopant are its abundance in nature, cost, or purely technological issues, like solubility or diffusivity.

Due to a very large $(3.4 \mathrm{eV})$ energy bandgap the intrinsic carrier concentration in $\mathrm{GaN}$ is very low. To create a p-n junction and consequently a working semiconductor device, as in any other semiconductor material incorporation of dopant elements with reasonably shallow energy levels is needed. It should be noted here that $\mathrm{GaN}$ is never free of background impurities, for example Si that can come from the quartz parts of the growth reactors. Therefore, without intentional compensation by other impurities undoped $\mathrm{GaN}$ is usually $n$-type and is often denoted in the literature as unintentionally doped (UID) GaN. Efficient $p$-type doping, in contrast to $n$-type doping is more problematic.

Several elements from group II and IV of the Periodic table were tried as $p$-type dopants in the past. After initial attempts with $\mathrm{Zn}, \mathrm{Cd}$, and $\mathrm{Be}$ [49] $\mathrm{Mg}$ was established as the only working $p$-type dopant. $\mathrm{Mg}$ is a group IIA element, an alkaline earth metal, atomic number 12, one of the most abundant elements on Earth. When it substitutes Ga in GaN lattice it acts as an acceptor and creates quite a deep level, $230 \mathrm{meV} . \mathrm{Mg}$ atoms are known to be passivated by $\mathrm{H}$ that is always present as carrier gas in HVPE and MOCVD processes. To break Mg-H complexes thermal annealing or low energy electron-beam irradiation (LEEBI) should be used. Hole concentrations were shown to increase from $2 \times 10^{15} \mathrm{~cm}^{-3}$ to $3 \times 10^{18} \mathrm{~cm}^{-3}$ after LEEBI [50]. Due to the deepness of the introduced level high concentrations of $\mathrm{Mg}\left(10^{19}\right.$ $-10^{20} \mathrm{~cm}^{-3}$ ) must be incorporated to obtain reasonable hole concentrations. In this thesis $\mathrm{Mg}$ doping and its implications for optical spectra and structural properties of both polar and nonpolar homoepitaxial GaN are considered in Papers 1-4.

Silicon is a widely used material in electronics, a group IVA element, atomic number 14. As it is situated between period III material Ga and period V material $\mathrm{N}$ it can act as both donor and acceptor depending on which atom it substitutes. First principles calculations show however that substitution of $\mathrm{Ga}$ is more preferential [51]. Thus upon substitution it creates a shallow donor level $\sim 30 \mathrm{meV}$ below conduction band [52]. Oxygen is a group VA element, it substitutes $\mathrm{N}$ and acts as a donor with a shallow level at $\sim 33 \mathrm{meV}$ [52]. Both $\mathrm{Si}$ and $\mathrm{O}$ can be present even in undoped samples and make it UID. Intentional doping by $\mathrm{O}$ and $\mathrm{Si}$ in HVPE grown bulk GaN layers was considered in Paper 5 of this 
thesis. Influence of $\mathrm{Si}$ doping on optical and structural properties of nonpolar m-plane homoepitaxial GaN was studied in Paper 6.

Carbon lies just above Si in IVA group of the Periodic table and therefore possesses amphoteric properties as a dopant, it can become a donor when it substitutes Ga and an acceptor when it substitutes $\mathrm{N}$. Theoretical calculations have shown, however, that substitution of $\mathrm{N}$ is preferred [53]. Due to a small radius it can also take an interstitial place. Initially $\mathrm{C}$ was considered as a potential p-type dopant, but all efforts to obtain p-type $\mathrm{GaN}: \mathrm{C}$ resulted in highly resistive, semi-insulating layers. These layers turned out to be useful in HEMT devices. High resistivity may be attributed to self-compensation of $C_{N}$ with $C_{I}[54]$ or $\mathrm{C}_{\mathrm{Ga}}$ [53]. There is a controversy whether $\mathrm{C}$ creates shallow or deep acceptor level in the bandgap. A more detailed discussion of substitutional $\mathrm{C}$ and its influence on yellow luminescence (YL) line and near bandgap emission (NBE) in HVPE grown bulk GaN are presented in Paper 7. 


\section{Optical Transitions in GaN}

We can excite electrons from the valence band to the conduction band by means of heat, electromagnetic energy or electron bombardment. To release the excess energy electrons and holes move to their equilibrium states. They can do it non-radiatively, by interacting with phonons, or radiatively, i.e. by emitting photons. Non-radiative recombination is considered unwanted as it produces heat instead of light and lowers quantum efficiency. In case of excitation by light the emitted luminescence is called photoluminescence and in case of excitation by electron beam the emitted light is called cathodoluminescence.

During the radiative recombination excited electron can return directly to the valence band. The emitted photons in this case have the energy equal to $E_{g}$. This luminescence is called band edge luminescence. Another situation is when the excited charge carriers get trapped on the shallow impurity levels. Recombination involving electrons and holes trapped on the impurity levels or annihilation of excitonic complexes bound to impurities provide a way to probe different dopants introduced into the material. Radiative transitions related to impurities are shown in Fig. 4.1. They are discussed in more detail below.

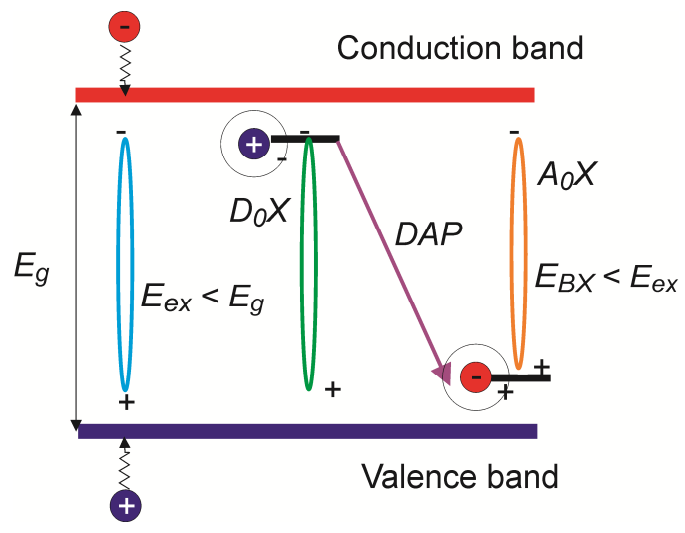

Fig. 4.1 Schematic drawing of important optical transitions in GaN. 


\subsection{DONOR-ACCEPTOR PAIR RECOMBINATION}

Donor and acceptor levels are depicted by the short lines inside the bandgap (Fig. 4.1). A direct recombination of excess electron from the donor level with the hole bound to the acceptor level is possible and called donor-acceptor pair (DAP) recombination. Donor and acceptor atoms are neutral before and become charged after the recombination, therefore Coulomb interaction energy is added to the radiative recombination energy:

$$
\hbar \omega_{D A}=E_{g}-E_{D^{0}}-E_{A^{0}}+\frac{e^{2}}{4 \pi \varepsilon \varepsilon_{0} r_{D A}}-m \hbar \omega_{L O},
$$

where $\hbar$ is Planck's constant, $E_{g}, E_{D^{0}}$, and $E_{A^{0}}$ are bandgap energy, donor activation energy, and acceptor activation energy, respectively, $e$ is electron charge, $\varepsilon$ is dielectric constant of the material, $\omega_{D A}, \omega_{L O}$ are DAP transition frequency and longitudinal optical phonon frequencies, and $m$ is an integer number.

DAP lines in GaN appear at $3.25-3.27 \mathrm{eV}$ followed by two LO phonon replicas due to phonon-assisted recombination. DAP emission involves recombination of holes from a shallow acceptor, e.g., $\mathrm{Mg}$ with activation energy $230 \mathrm{meV}$, and shallow donor, e.g., Si with activation energy $\sim 30 \mathrm{meV}$ or $\mathrm{O}$ with activation energy $\sim 33 \mathrm{meV}$ [55]. DAP can only be detected at lower temperatures as it quenches at $\sim 150 \mathrm{~K}$.

\subsection{EXCITONS IN GAN}

When an electron is excited to the conduction band leaving a hole in the valence band, three fundamental processes can occur. Firstly, if the electron and the hole get drawn back together by the Coulomb force the electron-hole pair annihilates giving off a photon, which contributes to the band edge luminescence. Secondly, if the electron has high enough energy that it can "escape" from the hole - the electron and the hole become free charge carriers. Then if we separate them, by for example applying an electric field, they give rise to photocurrent - this is how photodetectors and solar cells basically work. The third case is 
intermediate: the electron in the conduction band and the hole in the valence band can be bound together by an electrostatic Coulomb attractive force, forming an electron-hole pair, which is called an exciton. The exciton can move through the crystal and can be characterized by wave vector $K$. Excitons are unstable and undergo recombination process. The lifetime of free excitons in $\mathrm{GaN}$ is of the order of hundreds of picoseconds [56].

Thus, exciton is an electrically neutral quasi-particle consisting of the bound an electron and a hole separated in space. Generally excitons are divided into two kinds: more tightly bound, the so-called Frenkel excitons, with typical binding energy in the range 0.1-1 $\mathrm{eV}$ and more weakly bound, Wannier-Mott (WM) excitons, with typical binding energy of $\sim 0.01-0.03 \mathrm{eV}$. GaN possesses a reasonably high dielectric constant, $\varepsilon=8.9$, therefore electrostatic field in electron-hole pair is reduced and only weakly bound WM excitons with energies of $\sim 25 \mathrm{meV}$ are present.

Exciton movement can be described by the following Schrödinger equation:

$$
\left[-\frac{\hbar^{2}}{2 M} \nabla^{2} \vec{R}-\frac{\hbar^{2}}{2 \mu} \nabla^{2} \vec{r}-\frac{e^{2}}{4 \pi \varepsilon \varepsilon_{0} r}\right] \psi(\vec{R}, \vec{r})=\left(E-E_{g}\right) \psi(\vec{R}, \vec{r}),
$$

where the first term in Hamiltonian is kinetic energy of exciton translational movement with a center of mass coordinate $\vec{R}=\left(m_{e}^{*} \vec{r}_{e}+m_{v}^{*} \vec{r}_{v}\right) /\left(m_{e}^{*}+m_{v}^{*}\right)$, the second term is kinetic energy of rotational movement of electron around hole with a relative radius vector $\vec{r}=\vec{r}_{e}-\vec{r}_{h}$, and the third term is Coulomb interaction potential; $m_{e}{ }^{*}$ and $m_{h}{ }^{*}$ are the effective masses of electron and hole, $M=m_{e}^{*}+m_{h}^{*}$ is the mass of an exciton, $\mu=m_{c}^{*} m_{v}^{*} /\left(m_{c}^{*}+m_{v}^{*}\right)$ is reduced electronhole mass. Energy $E$ is counted from the top of the energy bandgap $E_{g}$.

Translational and rotational movements are independent, therefore the wave function can be presented as follows:

$$
\psi(\vec{R}, \vec{r})=\chi(\vec{R}) \varphi(\vec{r})
$$

Then if we divide eq. (4.2) by eq. (4.3) we can get two independent equations:

$$
-\frac{\hbar^{2}}{2 M} \nabla_{R}^{2} \chi(\vec{R})=W \chi(\vec{R})
$$




$$
-\frac{\hbar^{2}}{2 \mu} \nabla_{r}^{2} \varphi(r)-\frac{e^{2}}{4 \pi \varepsilon \varepsilon_{0} \vec{r}} \varphi(\vec{r})=\varepsilon \varphi(\vec{r})
$$

Equation (4.5) is almost the same as for electron movement in the hydrogen atom. Compared to hydrogen, instead of an electron, a quasi-particle with mass $\mu$, is rotating around positively charged center and electrostatic attraction is diminished by value of dielectric constant of the host material $\varepsilon$. The sum of energy eigenvalues $W$ and $\varepsilon$ are equal to the energy in (4.2):

$$
W+\varepsilon=E-E_{g},
$$

where $W=\frac{\hbar^{2} K^{2}}{2 M}$ is kinetic energy of the exciton and $\varepsilon=-\frac{\mu e^{4}}{8 \varepsilon_{0}^{2} \varepsilon^{2} h^{2} n^{2}}$ is excitonic potential energy. The dispersion relation for excitons can therefore be expressed from (4.6) as follows:

$$
E_{e x}=E_{g}-\frac{\mu e^{4}}{8 \varepsilon_{0}^{2} \varepsilon^{2} h^{2} n^{2}}+\frac{\hbar^{2} K^{2}}{2 M}
$$

The second term in expression (4.7) can be rewritten as $\frac{R y^{*}}{n^{2}}$, where $R y^{*}=\frac{\mu e^{4}}{8 \varepsilon_{0}^{2} \varepsilon^{2} h^{2}}$ is excitonic Rydberg, i.e. excitonic ground state energy at $n=1$. Compared to hydrogen, exciton binding energy is weaker by $\frac{\mu}{m_{e} \varepsilon^{2}}$. Excitonic spectra can therefore be imagined as a hydrogen-like series of emission lines with $\mathrm{n}=1,2,3, \ldots$ (Fig. 4.2). The valence band in $\mathrm{GaN}$ is split into three subbands due to the crystal-field splitting and spin-orbital coupling [57], consequently excitons involving a hole from each of the subbands can be observed - A, B, and $\mathrm{C}$.

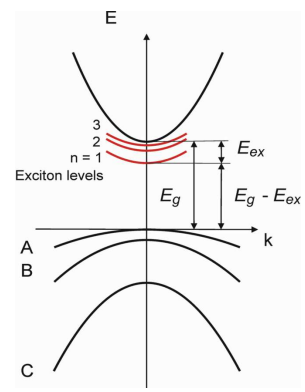

Fig. 4.2. Schematic drawing of energy dispersion curves of $\mathrm{GaN}$ at $\Gamma$ point of Brillouin zone. 
Exciton generated through absorption of a photon should have the same impulse value $K=K_{p h}$. Photon impulse is very small in the visible area, as $K_{p h}=\frac{h v}{c} \approx 0$, therefore excitonic impulse is also $K \approx 0$. This fact means that excitonic transitions are only possible to the bottom of the excitonic energy zones resulting in characteristic sharpness of excitonic emission lines. At $K \approx 0$ where direct transitions occur, excitonic spectra can be described then as follows:

$$
E_{e x}=E_{g}-\frac{R y^{*}}{n^{2}}
$$

By analogy with hydrogen atom excitonic Bohr radius can be written as:

$$
a^{*}=\frac{4 \pi \varepsilon_{0} \hbar^{2}}{m_{e} e^{2}}=\frac{\varepsilon m_{0}}{\mu} a_{0}
$$

Bohr radius is also modified and is larger than in hydrogen by a $\frac{\varepsilon m_{0}}{\mu}$ factor. Typical excitonic Rydberg energies and Bohr radii in semiconductors are in the range:

$$
\begin{gathered}
1 \mathrm{meV} \leq R y^{*} \leq 200 \mathrm{meV} \ll E_{g} \\
a_{\text {lattice }}<1 \mathrm{~nm} \leq a^{*} \leq 50 \mathrm{~nm}
\end{gathered}
$$

For GaN, these values are: $R y^{*}=25.2 \mathrm{meV}$ and $a^{*} \approx 30 \AA$ [58]. Ionized dopants in semiconductor contribute charge carriers that at high concentrations can screen, i.e. diminish, the Coulomb interaction between holes and electrons thereby destroying WM excitons. Parameter that describes the charge carrier screening is called the Debye length:

$$
d=\sqrt{\frac{\varepsilon \varepsilon_{0} k T}{e^{2} N}}
$$

If $a^{*}>d$ then excitons get destroyed by the Coulomb screening. As it follows from formula (4.12) two factors define the existence of excitons: temperature $T$ and concentration of charge carriers $N$. Generally excitonic lines can therefore be only observed at lower temperatures and in materials with relatively low charge carrier concentrations. In GaN we can observe excitonic emissioins at room temperature, as $\mathrm{Ry} *>25 \mathrm{meV}$. 


\subsection{BOUND EXCITONS (BE)}

Dopant atoms, incorporated into GaN, have different electronegativity compared to $\mathrm{Ga}$ or $\mathrm{N}$ therefore they can act as small potential wells, thus, creating a trap either for a hole or en electron. The trapped hole or electron can then attract an electron or a hole respectively and create a BE state. Excitons can be bound to neutral or ionized donor or acceptor atoms or other point defects, e.g., vacancies, or even extended defects, e.g., SFs. Binding of exciton to neutral acceptor and donor atoms and their recombination process are depicted in Fig. 4.3. When BEs recombine they emit energy that can be expressed as follows:

$$
h \omega=E_{g}-E_{e x}-E_{B X},
$$

where $E_{B X}$ is the binding energy of the exciton to the donor or acceptor atom. BE lines therefore appear before the free exciton (FE) lines in the emission spectra. Because BE are more localized than FE their kinetic energy is lower than FE kinetic energy, consequently BE emission lines are sharper then FE lines. BE emission is important for characterization purposes since it can serve as optical signature for defects and impurities.
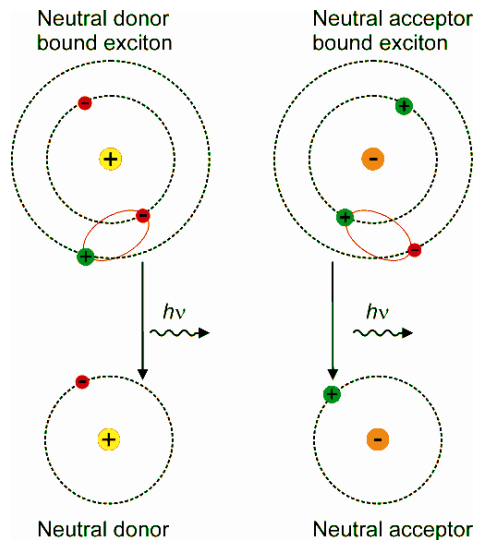

Fig. 4.3. Schematic drawing of bound exciton electronic structure and the corresponding recombination process. 
DAP, FE, and BE emissions are commonly called near bandgap emission (NBE). A typical spectrum of NBE from $c$-plane HVPE-grown GaN layer is shown in Fig. 4.4. Besides DAP (at the inset, larger scale), FE lines, acceptor and donor BE we can see longitudinal optical (LO) phonon replicas of the same peaks in the $3.35-3.40 \mathrm{eV}$ region. LO phonon interaction induces phonon-assisted exciton emissions accompanying the exciton recombination. The ratio of the exciton peak intensities to the intensities of phonon replicas can serve as a measure of exciton-phonon interaction.

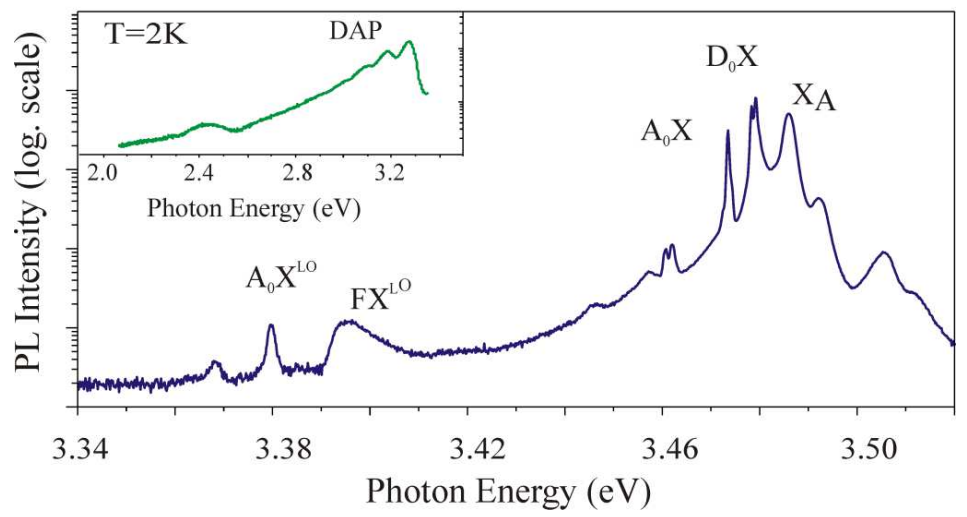

Fig. 4.4. Low-temperature photoluminescence spectrum of nominally undoped HVPE GaN layer grown on sapphire. Courtesy of Dr. G. Pozina.

\subsection{YELLOW LINE (YL)}

The ubiquitous YL is very often present in GaN emission spectra. It is centered around $2.2 \mathrm{eV}$ and has a broad near Gaussian form. It is detrimental to device efficiency as it competes with the NBE emission that produces the needed UV and violet light. YL was observed in both undoped, i.e. unintentionally n-type doped samples, and in GaN doped with different dopant impurities. Several researchers reported enhancement of the YL due to C doping [59], [60]. Some others reported its relation to Gallium vacancies $\mathrm{V}_{\mathrm{Ga}}$ [61] or to recombination between $\mathrm{O}_{\mathrm{N}}$ and $\mathrm{V}_{\mathrm{Ga}}$ [62], [63]. The origin of the YL therefore remains 
controversial. Fig. 4.5 shows a typical spectrum from C-doped HVPE grown bulk GaN with YL and FE emission lines.

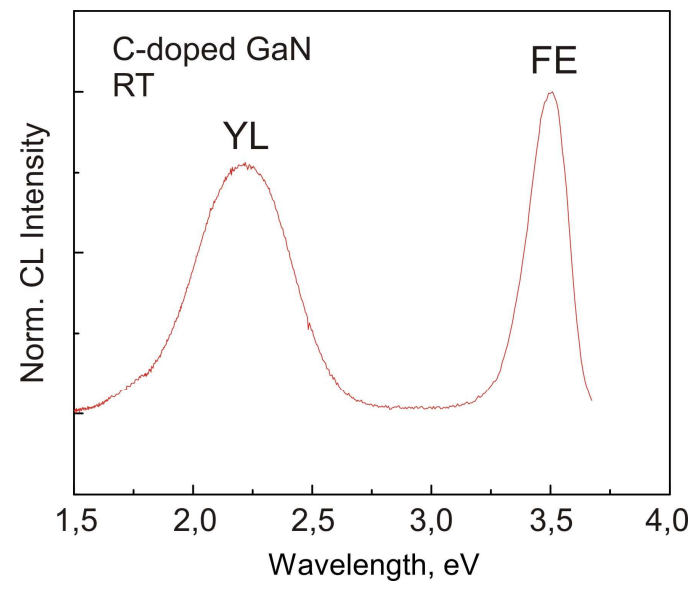

Fig. 4.5. A typical spectrum from C-doped GaN layers showing YL and FE emissions. 


\section{Extended Defects in GaN}

It was mentioned in the introduction that low availability of cheap and high quality native substrates drives manufacturers to grow $\mathrm{GaN}$ on foreign substrates, such as $\mathrm{SiC}$ or sapphire. It results in high strain fields due to lattice mismatch and difference of temperature expansion coefficients between the epitaxial film and the substrate, which in turn leads to high density of extended defects, such as threading dislocations (TD) and SFs. Extended defects proved to have limited effect on device performance and working devices exist despite extremely high density of TDs in the range $10^{8}-10^{9} \mathrm{~cm}^{-2}[10]$ and SFs in the range $10^{5}-10^{6}$ $\mathrm{cm}^{-2}$ [64]. However, they do influence device performance, e.g. TDs can act as scattering centers thus lowering carrier mobility [65], and non-radiative recombination centers which lowers quantum efficiency [11]; SFs were linked with higher leakage currents [66]. Therefore, to produce new generations of LEDs, the density of extended defects must be lowered [67] and a lot of research is focused in this direction.

\subsection{THREADING DiSLOCATIONS}

There are normally three types of TDs in c-plane GaN (Fig. 5.1): perfect edge (a-type) dislocations with Burger vector $\mathbf{b}=\frac{1}{3}\langle 11 \overline{2} 0\rangle$ and line vector $\mathbf{J}=\langle 0001\rangle$, they constitute 40$70 \%$ of all dislocations [68]; perfect screw dislocations (c-type) with $\mathbf{b}=\langle 0001\rangle$ and $\mathbf{J}=$ $\langle 0001\rangle$, they are the most uncommon type and are 1-2\% of all dislocations [65], [69]. The rest are mixed type dislocations ( $a+c$-type) with $\mathbf{b}=\frac{1}{3}\langle 11 \overline{2} 3\rangle$ and $\mathbf{J}$ about $12^{\circ}$ inclined from the [0001] direction [65]. 

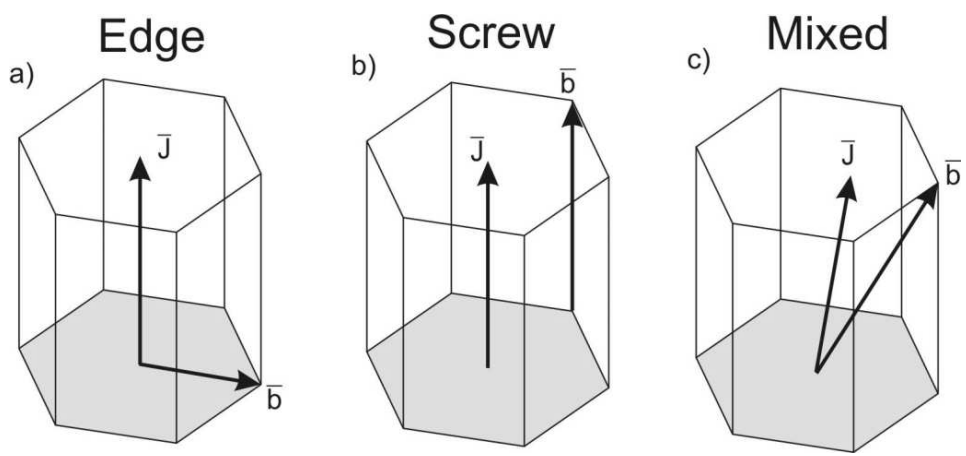

Figure 5.1. Dislocation types in $\mathrm{GaN}$ and their corresponding Burger vectors $\mathbf{b}$ and line directions J. a) Edge dislocation (a-type). b) Screw dislocation (c-type). c) Mixed dislocation $(a+c$-type).

There is controversy regarding the origin of TDs. Ning et al. [70] proposed that the rotation of the coalescence islands during the initial growth stages results in TD formation. They suggested that rotation of the islands around [0001] axis leads to their tilt and consequent formation of edge TDs while rotation around axes perpendicular to [0001] leads to their twist and screw TDs formation (Fig. 5.1). These findings were supported by Wu et al. [71]. On the other hand Narayanan et al. [72] in their studies stated that TDs come from the defects at the sapphire/GaN boundary.
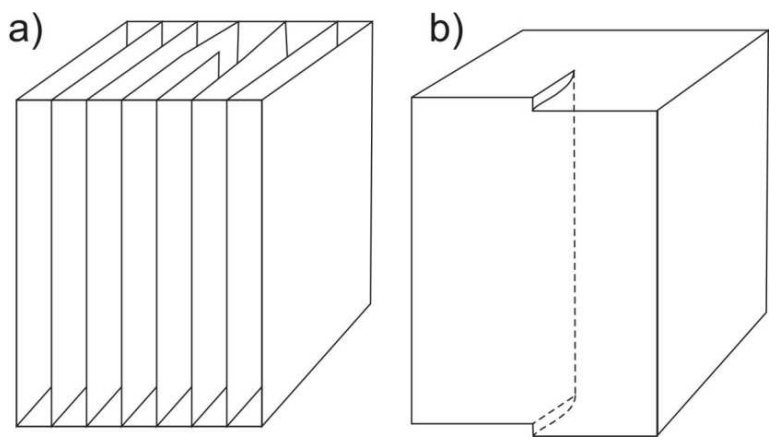

Figure 5.2. a) Perfect edge dislocation. b) Perfect screw dislocation.

Different methods are used to lower the TD density, such as epitaxial lateral overgrowth, pendeo epitaxy [73], applying high-temperature AlN buffer layers [67] or transitional metal nitrides interlayers [74]. These techniques allowed to lower the dislocation density by a few orders of magnitude to $\sim 10^{6}-10^{7} \mathrm{~cm}^{-2}$. 


\subsection{STACKING FAULTS}

SFs are normally observed in nonpolar GaN [75],[64], but can also be detected in $c$ plane GaN, Paper 1. Three kinds of BSFs are typical for GaN, two intrinsic ones $-I_{l}$ and $I_{2}$, and one extrinsic $-E$, Fig. 5.3.

a)
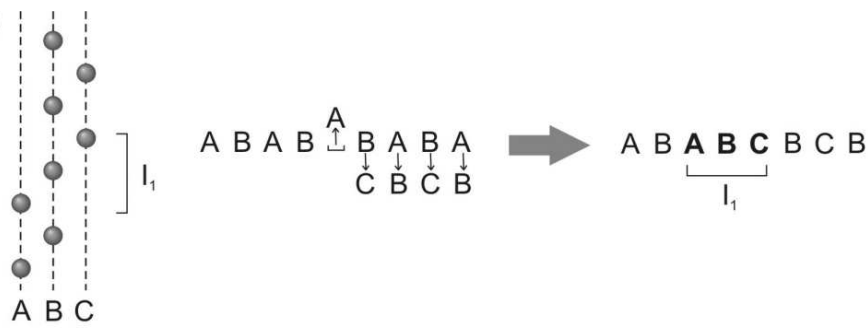

b)

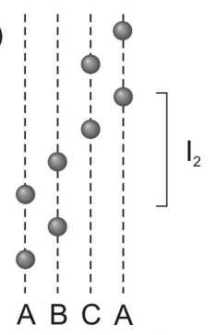

A B A B A B A B

$\stackrel{\downarrow}{C} \stackrel{\downarrow}{\perp} \stackrel{\downarrow}{C} \stackrel{\downarrow}{\perp}$

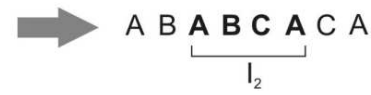

c)

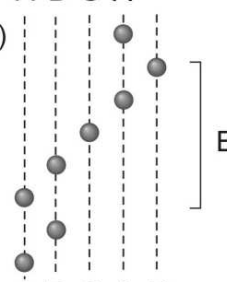

$C$

E $A B A B B^{\downarrow} A B B$

A B A B C A B A B

A B C A B

Figure 5.3. Stacking sequence of GaN with three types of BSFs. (a) Intrinsic BSF of type 1. (b) Intrinsic BSF of type 2. (c) Extrinsic BSF. Only atoms from one of the sublattices (Ga) are shown for clarity.

Intrinsic BSF of type $I_{l}$ is formed by removing one layer (e.g., Aa) in hexagonal $\mathrm{AaBbAaBb}$ stacking followed by slip of the rest of the crystal by $\frac{1}{3}\langle 10 \overline{10}\rangle$ to reduce the fault energy. This type of SF is bound by Frank partial dislocation with Burger vector $\mathbf{b}=$ $\frac{1}{6}[2 \overline{2} 03] . I_{2}$ SF is a result of direct shearing by $\frac{1}{3}\langle 10 \overline{10}\rangle$ of one part of the crystal in respect to the other or, alternatively, by dissociation of a perfect dislocation into two Shockley partial 
dislocations with Burger vectors $\mathbf{b}=\frac{1}{3}\langle 1100\rangle$. Extrinsic SF is formed by insertion of an extra layer of atoms in the stacking and bound by Frank partials of type $\mathbf{b}=\frac{1}{2}[0001]$ [64].

SFs can be imagined as a thin lamella of zinc blende $\mathrm{GaN}$ introduced in the wurtzite lattice, each of them possessing a characteristic SF energy $\gamma$. The magnitude of $\gamma$ depends on the number of violations in the stacking sequence of the planes [76]. $I_{1} \mathrm{SF}$ involves one change, $I_{2} \mathrm{SF}$ - two changes and $E \mathrm{SF}$ - three changes. Ratios of energies for different kinds of SFs can roughly be written as $\gamma_{\mathrm{E}} \approx \frac{3}{2} \gamma_{\mathrm{I}_{2}} \approx 3 \gamma_{\mathrm{I}_{1}}$. $I_{l}$ SF has the lowest energy and therefore should be the most probable type of SFs. This is supported by the experiments $-I_{l}$ is the most commonly observed SF, followed by $I_{2}$ and $E$ types.

Besides BSFs, prismatic SFs (PSF), i.e. SFs on the planes perpendicular to $c$-plane, are also observed, for example faults on $(\overline{12} \overline{10})$ plane with fault vector $\mathbf{R}=\frac{1}{2}[10 \overline{11}]$. They were also found to terminate BSF [64].

The formation mechanism of SF is complex and poorly understood. It was proposed that SF are formed during growth process due to small difference in formation energies between wurtzite and cubic phases; another mechanism is impurity-induced SF formation [77].

SFs, in contrast to TDs, can be radiatively active. The zinc blende polytype of GaN has a lower bandgap energy of $3.2 \mathrm{eV}$ compared to wurtzite structure with the bandgap energy of $3.4 \mathrm{eV}$ at room temperature. Therefore, $\mathrm{SF}$ can be considered as a thin inclusion of cubic GaN and play a role of a QW where charge carriers can be confined. Excitons can be trapped by localization potential related to SF and recombine giving characteristic emission lines in the region 3.29-3.41 eV (Fig. 5 in Paper 1) [75]. It is agreed that these lines are related to SFs and partial dislocations terminating SFs, however, there is still no clarity in the attribution of these peaks. 


\section{Characterization Techniques}

\subsection{TRANSMISSION ELECTRON MICROSCOPY}

TEM is a versatile microscopy technique that provides a wealth of information about morphology, composition, and crystallographic properties of the studied samples. The resolving power of a microscope is defined by the classical Rayleigh criterion and ultimately limited by the wavelength of radiation. Compared to photons, electrons have significantly smaller wavelength, therefore a much better resolution can be obtained if electrons are used instead of visible light, which is realized in TEM. The wavelength of electrons depends on their energy and defined by the following equation [78]:

$$
\lambda=\frac{\mathrm{h}}{\sqrt{\left(2 \mathrm{~m}_{0} \mathrm{eV}\right)}},
$$

where $\mathrm{h}$ is Planck constant, $\mathrm{m}_{0}$ is electron mass, and $\mathrm{V}$ is a potential drop.

A typical value for beam energy $(\mathrm{E}=\mathrm{e} \cdot \mathrm{V})$ in modern TEMs is $200 \mathrm{keV}$, then from equation (6.1) electron wavelength $\lambda$ is equal to $\sim 2.7 \mathrm{pm}$. Compared to lenses in optical microscopy, however, electromagnetic coils that are used as lenses in TEM are very inefficient, therefore practical resolution is smaller in practice, around $1 \AA$. This means that atomic size resolution is possible in TEM.

A typical design of a TEM is shown in Fig. 6.1. A highly energetic electron beam, generated by a field-effect emission gun, passes in a vacuum column through a series of condenser lenses and apertures that control beam's size and intensity. The amount of electric current flowing in the electromagnetic coil defines the strength of the lens. The beam interacts with a thin specimen, which is $<100 \mathrm{~nm}$ thick, part of the beam is transmitted and focused 
below the specimen by the objective lens, magnified by intermediate and projected by projection lenses onto the screen of a CCD camera.

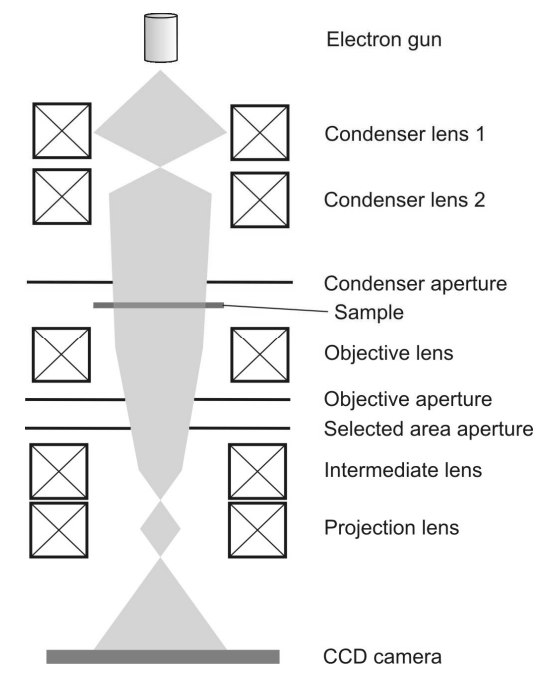

Figure 6.1. Schematic drawing of TEM.

A number of different imaging techniques and modes exist in TEM. Bright field (BF) imaging mode is the mode where only the transmitted beam is used to form the image: the central spot of diffraction pattern is chosen by introducing the objective aperture, filtering out most of the scattered electrons. Dark field (DF) mode, on the contrary, uses only the scattered electrons, by choosing spots other than the central one in the diffraction pattern. DF gives inverse and improved contrast relative to $\mathrm{BF}$, which is advantageous for imaging smaller features in the crystal, such as extended defects. The contrast in BF and DF imaging is governed by diffraction phenomena.
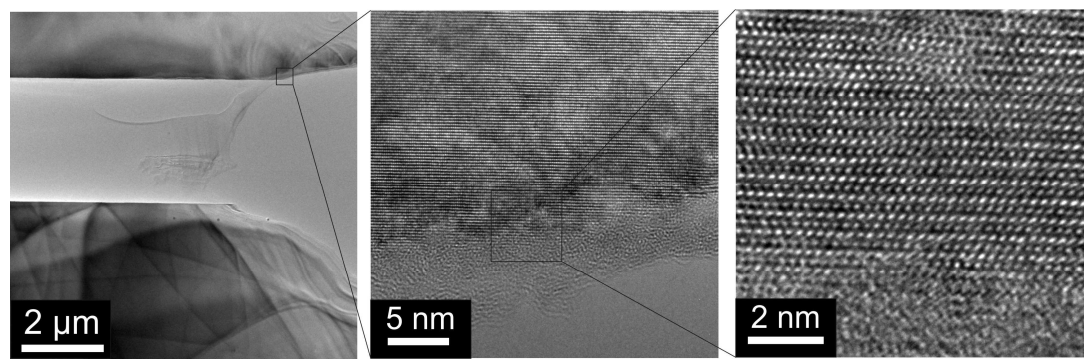

Fig. 6.2. Examples of TEM (a) and HRTEM images (b, c) of GaN. 
At lower magnifications mass-thickness contrast prevails: thicker or denser areas appear darker, whereas thinner and lighter areas appear lighter. In high resolution TEM (HRTEM) the contrast is produced by phase-contrast mechanism: when interacting with atom potentials electron wave undergoes phase shift, after the interaction, transmitted and scattered beams interfere to produce the contrast allowing for lattice resolution imaging. An example of a TEM image at low magnification, where mass-thickness and diffraction contrast dominates and two HRTEM images at higher magnifications where phase contrast allows resolution of lattice fringes and even single atom columns are shown in Fig. 6.2.

Besides BF or DF images electron diffraction patterns give us information about the crystallography, orientation, and defects in the sample. The main drawback of TEM is, however, the long and laborious sample preparation: cutting, grinding and ion milling are needed to make an electron transparent, less than $100 \mathrm{~nm}$ thin, TEM sample.

\subsection{SCANNING TEM AND ENERGY-DISPERSIVE X-RAY SPECTROSCOPY}

Scanning TEM (STEM) is a TEM technique, where instead of illuminating the sample with a parallel beam, a convergent beam is used to probe it. The electron rays are condensed by the lenses to a fine spot $(<1 \mathrm{~nm})$ and scanned by means of scanning coils across the sample surface. Normally, high angle annular dark field (HAADF) detector is used to detect the signal. The contrast in this case is Z-contrast, i.e. intensity in the resulting image depends on the atomic scattering factor.

The power of TEM lies not only in the possibility for high magnification and for examining of the fine details, but also in extensive analytical capabilities available in the STEM mode. One of these techniques is energy-dispersive X-ray spectroscopy (EDX). When the electron beam impinges onto the surface of the sample, a great number of different signals is generated, among which X-rays are emitted. The energy of the X-rays is defined by the electronic structure of the constituent atoms in the material, therefore EDX scans give a 
picture of elemental composition in the sample. EDX is more suited for detecting heavier element atoms due to detector sensitivity limitations.

\subsection{SCANNING ELECTRON MiCROSCOPY AND CATHODOLUMINESCENCE}

Scanning electron microscopy (SEM) is a microscopy technique that uses a condensed electron beam rastered with scanning coils across the sample to produce an image with nanometer resolution. Compared to TEM much lower beam energies are used in SEM, in the range of 5-40 kV. SEM is widely used both in industry and academia as a tool for examination of microstructure and morphology of the films, since it is a nondestructive, simple and quick characterization technique. The concentrated beam is generated in high vacuum chamber $\left(10^{-10}\right.$ Torr) by field emission gun and formed by several magnetic condenser lenses to a size of $\sim 1 \mathrm{~nm}$. The size of the probe is dependent on the accelerating voltage, e.g., it is $1.2 \mathrm{~nm}$ at $20 \mathrm{kV}$ and 2.5 at $5 \mathrm{kV}$. Samples with high dielectric constant, such as $\mathrm{GaN}$ on sapphire substrate, can accumulate charge therefore they are glued to the sample holder with, for example, conducting Ag paste to drain the charge and improve the image quality. A wealth of signals is generated during electron-specimen interactions that are originating from different depths of the interaction volume - the volume area where the incident electrons penetrate in the sample material, Fig. 6.3.

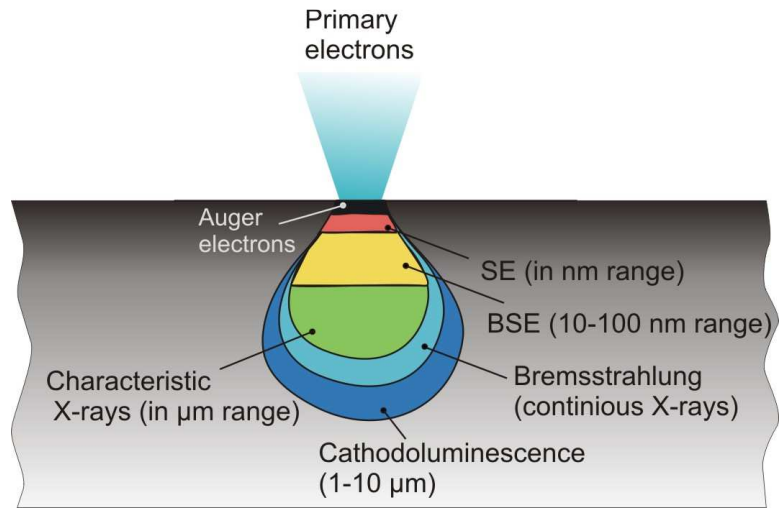

Fig. 6.3. Signals generated in SEM during electron-specimen interaction. 
Primary electrons can knock out electrons from the inner atomic shells of the material. These electrons are called secondary electrons (SE) and are of quite small energy, $<50 \mathrm{eV}$, therefore they can escape the sample only if they are generated in the near surface area, several nanometers from the top. Consequently they carry the topographical information of the specimen and are used to observe surface morphology for example. Electrons from the primary beam that bounce back elastically are called backscattered electrons (BSE), their energy is much higher than SE energy, several 1000s of eV. Backscattering is strongly dependent on $\mathrm{Z}$, atomic number of the constituent atoms, and is used to observe chemical variations in the sample.

Similar to TEM, X-rays emitted as a result of electron excitation and relaxation on the inner shell atomic orbitals can be collected and used by a corresponding detector for quantitative compositional analysis. An alternative process is when this energy is released by emission of Auger electrons which can provide surface chemical information from the sample.

Cathodoluminescence (CL) is produced involving recombination of electrons and holes excited by the energetic primary electrons from valence electron levels, i.e. from valence band to conduction band. Photons emitted as a result of the recombination can be collected and analyzed by an optical system attached to SEM. A Gatan MonoCL4 system integrated with a LEO 1550 Gemini SEM was used in our experiments. Schematic diagram of the SEM-CL setup is shown in Fig. 6.4. To collect the emitted photons a special parabolic mirror made of aluminum is inserted into the SEM chamber. To maximize the signal the sample is positioned at the focal point of the mirror.

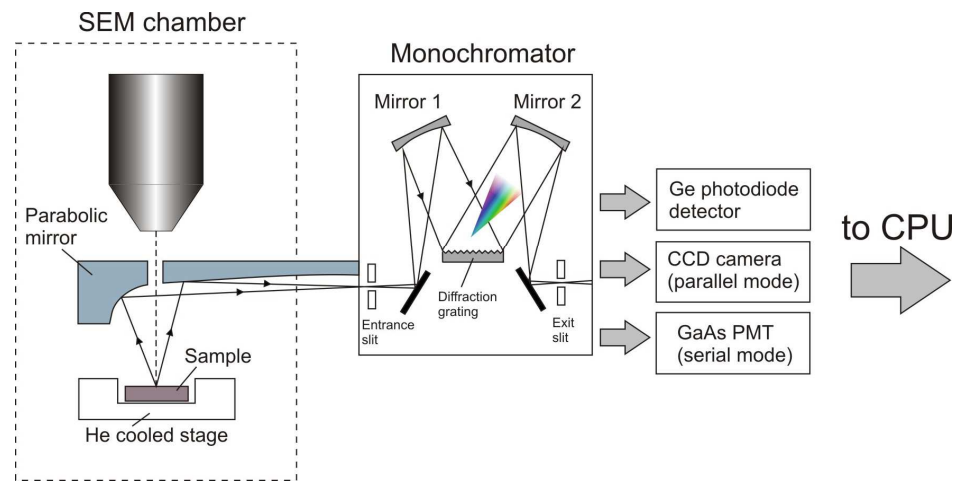

Figure 6.4. The MonoCL4 system at Linköping University. 
CL rays are bent and transferred to the monochromator box. Monochromator is an optical device that allows choosing separate wavelengths from emission of a broader spectrum. MonoCL4 system employs Czerny-Turner type monochromator, principal parts of which are two slits, two spherical mirrors and a diffraction grating. By choosing the appropriate slit width we can control the amount of light entering and exiting the monochromator. The first spherical mirror collimates the light, i.e. makes it parallel and directs it onto the diffraction grating. The purpose of the diffraction grating is to disperse the light into separate wavelengths. The extent to which the light is dispersed is defined by the density of the grooves (lines/mm) of the grating (ruling density). This extent is called dispersion and it is expressed in nanometers per millimeter of the slit width $(\mathrm{nm} / \mathrm{mm})$. The higher the ruling density the smaller is the dispersion, i.e. higher final resolution that is possible to achieve. On the other hand higher ruling density also means shorter usable wavelength range.

The final spectral resolution is defined by both the choice of diffraction grating and the width of the slits. Another important parameter, besides dispersion, that characterizes diffraction grating is a blaze wavelength, which is the wavelength that this grating is optimized for. In other words blazing is concentration of the emission energy into a particular wavelength ( $1^{\text {st }}$ order). The usable wavelength range of a diffraction grating is $0.6-1.5$ of the blaze. For different wavelength ranges, appropriate diffraction gratings should be chosen, for example for NBG luminescence in $\mathrm{GaN}$, we used gratings with $18001 / \mathrm{mm}$ with dispersion 2 $\mathrm{nm} / \mathrm{mm}$ and $1200 \mathrm{l} / \mathrm{mm}$ with dispersion $2.7 \mathrm{~nm} / \mathrm{mm}$.

There are two types of detectors that were used in our experiments: serial and parallel. Serial detectors are Ge photodiode and GaAs photomultiplier tube (PMT). Parallel detector is a Si CCD detector. In our experiments only CCD and PMT detectors were employed. When single channel detector, i.e. PMT is used, diffraction grating is stepped by stepper motor, each time a certain wavelength can be chosen by the exit slit. In this way wavelength vs. intensity plot is built. In parallel mode the CCD camera is used - in this case diffraction grating does not move and the whole spectrum is directed to CCD bypassing the exit slit.

Besides mere spectrum acquisition CL imaging is possible with our MonoCL4 system. In this case when sample is rastered with electron beam, light intensity is measured at each point thereby a CL mapping image is being built. Two operation modes are possible: 
panchromatic and monochromatic. In panchromatic mode all the light is sent to the detector, while in monochromatic mode it is let through the monochromator that chooses a particular wavelength. Monochromatic mode is particularly useful as it allows observing the optical properties of different defects and features in the sample at certain wavelengths. Spatial resolution in CL mapping is dependent on beam energy and is changing from $4 \mu \mathrm{m}$ at $30 \mathrm{kV}$ to about $1 \mu \mathrm{m}$ at 15 (where most of our experiments were performed) to $300 \mathrm{~nm}$ at $5 \mathrm{kV}$.

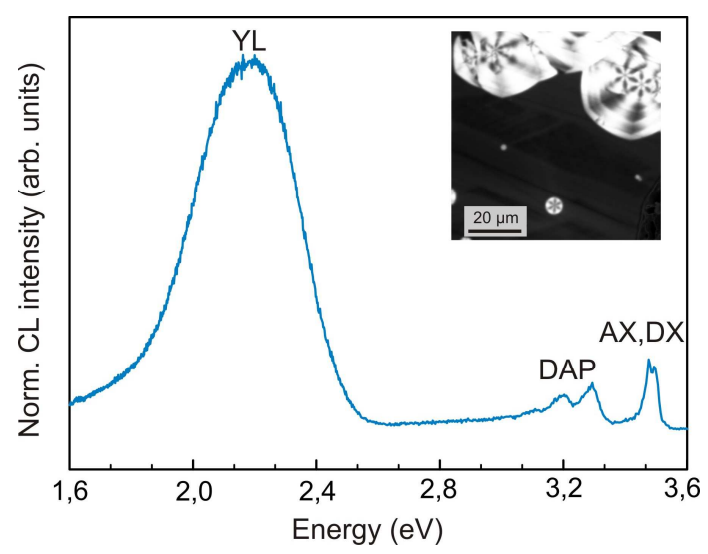

Fig. 6.5. A CL spectrum and a panchromatic CL mapping (inset) from a C-doped GaN.

A liquid He stage was used to do CL measurements at low temperatures. This allows to avoid thermal broadening of emissions, enhance radiative recombination and to be able to observe some recombinations that involve levels with low activation energies. An example of a CL spectrum and a panchromatic CL image (on the inset) of the same sample, recorded at $5 \mathrm{~K}$, are shown in Fig. 6.5. Direct comparison of structural features observed in SEM images with their optical properties obtained from CL spectra and CL mapping make the SEM-CL system a very powerful tool in characterization of GaN. 


\subsection{PHOtOLUMINESCENCE AND TIME-RESOLVED PHOTOLUMINESCENCE}

Photoluminescence is another nondestructive luminescence technique that can be used to probe the electronic structure of materials. In this method a laser source or a lamp with energy larger than the material bandgap is employed to excite electrons from valence band to conduction band. Electrons and holes recombine spontaneously either directly from conduction to valence band or involving different defect and excitonic levels in the bandgap. The emitted radiation is collimated, focused by lenses and directed to the monochromator that disperses the light into separate wavelengths. The dispersed light is then recorded by a detector and intensity vs. wavelength plot can be viewed on a computer screen. In our PL system at LiU stationary PL spectra were measured with above band gap continuous wave (cw) UV excitation (laser photon energy of $4.65 \mathrm{eV}$ ) with second harmonic $\lambda=266 \mathrm{~nm}$ of a solid state laser $(532 \mathrm{~nm})$. Typical size spot in PL is $50-100 \mu \mathrm{m}$ and penetration depth is several $\mathrm{nm}$. The detector used was a GaAs CCD camera. The sample is put into a liquid He cooled cryostat to allow measurement in a wide temperature range, $5-300 \mathrm{~K}$.

To study recombination dynamics of different excited states time-resolved photoluminescence (TRPL) was used. In this case charge carriers are excited by a short laser pulse, after that PL intensity vs. time of different emission lines can be observed. Decay times of most transitions in $\mathrm{GaN}$ are of the order of nano- and picoseconds. To get the desired time resolution a special device is used - a streak camera. The principal parts of it are a photocathode that turns the incoming photons into electrons, a sweep electrode and a phosphorous screen. A high voltage varied with time is applied to the sweep electrodes thereby time-deflecting the electrons, which then reach the phosphorous screen and create temporal profile of the light pulse. In TRPL setup, a Ti:sapphire femtosecond solid state laser was used, excitation was performed by the third harmonics $(\lambda=266 \mathrm{~nm})$ with a pulsed frequency of $75 \mathrm{MHz}$ and the laser power density of $\sim 100 \mathrm{~W} / \mathrm{cm}^{2}$. 


\subsection{ATOM PRoBe TOMOGRAPHY AND FocUSED ION BEAM}

Atom probe tomography (APT) is a destructive microscopy technique that provides both unique spatial, subnanometer resolution and quantitative elemental information with less than 10 ppm sensitivity. In the last ten years with the emergence of laser-pulsed APT the technique found application not only to conductive metallic samples, but also ceramics and semiconductors, in particular III-V materials. The schematic set-up for APT measurements is shown in Fig. 6.6. In APT, needle shaped samples are placed in an ultra-high vacuum chamber at constant accelerating voltage $(5-20 \mathrm{kV})$. Due to specimen sharpness (around 100 $\mathrm{nm})$ a very high field is created at sample apex. Pulsing laser then evaporates layer after layer of atoms that are collected by a position sensitive detector (PSD), time-of-flight (ToF) of the ions is recorded as well. ToF is then converted to mass-to-charge ratio (eq. 6.2) thereby elemental information is obtained:

$$
\begin{aligned}
& \frac{m v^{2}}{2}=q E \Rightarrow \frac{m}{q}=\frac{2 E t^{2}}{L^{2}}, \\
& L=v t
\end{aligned}
$$

where $E$ is applied electric field, $t$ is time of flight, $L$ is the distance between the sample and the detector, $m$ and $q$ are mass and charge of the ion, respectively. Based on ToF and position information an elemental 3D image of the sample can be reconstructed with sophisticated software. Advanced quantitative elemental analysis is possible after the reconstruction is done, e.g., study of clusters, precipitates or grain boundaries.

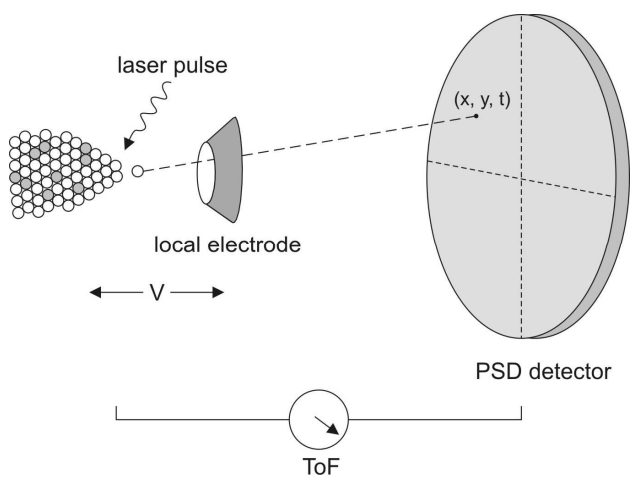

Fig. 6.6. Schematic illustration of an APT set-up. 
Needle shaped samples for APT are prepared by focused ion beam (FIB) technique. FIB is an SEM extended by addition of a liquid Ga ion source at $54^{\circ}$ angle to the SEM column. With the help of focused Ga ion beam specimen can be milled and cut with submicrometer precision. Besides sputtering out atoms and ions, Ga ions knock out SE so even imaging is possible in FIB mode (only at lower ion currents). The system is also equipped with a gas ion system (GIS) that allows depositing of different protective layers, typically Pt or W. GIS creates local gas atmosphere by emitting precursor gases that are broken down by the $\mathrm{Ga}$ beam resulting in deposition of the intended material - a process similar to CVD.

APT sample preparation in FIB involves several steps. First, a region of interest is selected and a protective Pt coating of $1-2 \mu \mathrm{m}$ is deposited in the form of a rectangle with the size of $15 \times 2 \mu \mathrm{m}$. Then a wedge is milled underneath this rectangle at $24^{\circ}$, which is later attached to a micromanipulator and cut loose. The wedge is then attached to a special holder, called flat top post (FTP), which is made of Si and looks like a $6 \times 6$ array of truncated cones with top diameter of $\sim 2 \mu \mathrm{m}$. The end of the wedge is repeatedly placed on the cones, glued by Pt and sliced. When a number of such slices is produced, they are circularly milled and polished with different voltages and ion currents to obtain the resulting needle shaped specimen with a $100 \mathrm{~nm}$ diameter. A thorough description of the APT sample preparation techniques can be found in [79]. 


\section{Summary of the Papers}

This thesis is concerned with the effects of doping on structural and optical properties of polar and nonpolar thin films and bulk $\mathrm{GaN}$ layers. Samples doped with $\mathrm{Mg}, \mathrm{Si}, \mathrm{O}$ or $\mathrm{C}$ were studied by TEM, SEM-CL, PL, and APT characterization techniques.

\section{Polar homoepitaxial GaN}

In Paper 1, Mg-doped c-plane oriented MOCVD homoepitaxial GaN layers grown by MOCVD were investigated. It was established that increasing $\mathrm{Mg}$ concentration coincides with increasing concentration of small-sized basal SFs. SF-related peaks were found in lowtemperature CL spectra. EDX scans gives indications that $\mathrm{Mg}$ resides at a distance of a few $\mathrm{nm}$ from a SF. I suggest that $\mathrm{Mg}$ acceptor atoms can perturbate the potential profile in the vicinity of a nearby SF and therefore an exciton can be bound to this atom making the SF optically active. Metastability of this emission is believed to be due to the exciton transfer to other defects.

In Paper 4, two $c$-plane GaN layers doped with rather high $\mathrm{Mg}$ concentrations were studied by a novel APT technique. In the sample with the highest $\mathrm{Mg}$ content $\left(1 \times 10^{20}\right.$ $\left.\mathrm{cm}^{-3}\right)$ clustering of $\mathrm{Mg}$ atoms was found in contrast to the lower doped sample $\left(5 \times 10^{19} \mathrm{~cm}^{-3}\right)$ with homogeneous Mg distribution. SFs were observed by TEM in both of these samples; however, the SF-related cathodoluminescence is prominent only in the lower doped sample. We explain SF's optical inactivity in the GaN sample with Mg clusters in terms of screening effect in the presence of $\mathrm{Mg}$ clusters that destroy exciton binding to the SF.

\section{Nonpolar homoepitaxial GaN}

Papers 2 and 6 are focused on nonpolar, $m$-plane homoepitaxial $\mathrm{GaN}$ layers doped with $\mathrm{Mg}$ and $\mathrm{Si}$, respectively. In Paper 2 layers were found to contain basal and prismatic SFs; however, a spectral region where the SF-related luminescence is observed was dominated by a series of sharp lines. The origin of these lines is not yet completely understood. The DAP nature of these features was ruled out by calculations. They can be associated with SFs, or 
with excitons bound to some point impurities. Several n-type, Si-doped $m$-plane homoepitaxial GaN layers were investigated in Paper 6. SFs were detected both in TEM and in the spatially resolved SEM and CL images. However, their optical signatures were observed only in the samples with lower Si concentrations. The localization of carriers or excitons at SFs cannot be realized in the lower doped layers, in contrast to the higher doped samples where carrier interaction is destroyed due to screening effect.

In Paper 3, the nature of the two acceptor states due to Mg doping in both polar (c-plane) and non-polar ( $m$-plane) homoepitaxial GaN is discussed. One of them (ABE1) is deemed a conventional substitutional acceptor state, while the other one (ABE2) is believed to be due to acceptor atom perturbed by the nearby SF.

\section{Bulk GaN}

In Papers 5 and 7, bulk GaN n-type layers doped with Si, O, and C were studied. Results from Paper 5 show that incorporation of $\mathrm{O}$ leads to a reduction of background $\mathrm{Si}$ concentration by one order of magnitude. Bandgap narrowing with $\sim 6 \mathrm{meV}$ was observed as well.

In Paper 7 correlation between $\mathrm{C}$ doping and increasing YL intensity was observed. Different luminescence properties of different, pits and pits-free areas, of the Cdoped layers were revealed by CL-mapping. Pits areas exhibit DBE lines, but no ABE lines, whereas pit-free areas are dominated by two ABE lines with no DBE lines. The difference is explained by a different $\mathrm{C}$ content in these areas. 


\section{Bibliography}

[1] F. A. Ponce and D. P. Bour, "Nitride-based semiconductors for blue and green lightemitting devices," Nature, vol. 386, pp. 351 - 359, 1997.

[2] D. V. P. McLaughlin and J. M. Pearce, "Progress in Indium Gallium Nitride Materials for Solar Photovoltaic Energy Conversion," Metall. Mater. Trans. A, vol. 44, no. 4, pp. 1947-1954, Feb. 2013.

[3] W. Shockley and H. J. Queisser, "Detailed Balance Limit of Efficiency of p-n Junction Solar Cells,” J. Appl. Phys., vol. 32, no. 3, p. 510, 1961.

[4] J. A. Van Vechten, "Quantum Dielectric Theory of Electronegativity in Covalent Systems. III. Pressure-Temperature Phase Diagrams, Heats of Mixing, and Distribution Coefficients," Phys. Rev. B, vol. 7, no. 4, pp. 1479-1507, 1973.

[5] H. P. Maruska, D. A. Stevenson, and J. I. Pankove, "Violet luminescence of Mgdoped GaN," vol. 303, 1973.

[6] H. Amano, N. Sawaki, I. Akasaki, and Y. Toyoda, "Metalorganic vapor phase epitaxial growth of a high quality GaN film using an AlN buffer layer," Appl. Phys. Lett., vol. 48, no. 5, p. 353, 1986.

[7] H. Amano, M. Kito, K. Hiramatsu, and I. Akasaki, "P-Type Conduction in Mg-Doped GaN Treated with Low-Energy Electron Beam Irradiation (LEEBI)," Jpn. J. Appl. Phys., vol. 28, p. L2112-L2114, 1989.

[8] S. Nakamura, T. Mukai, M. Senoh, and N. Iwasa, "Thermal annealing effects on p-type Mg-doped GaN films," Jpn. J. Appl. Phys., vol. 38, p. L139-L142, 1992.

[9] S. Nakamura, T. Mukai, and M. Senoh, "Candela-class high-brightness InGaN/AlGaN double-heterostructure blue-light-emitting diodes," Appl. Phys. Lett., vol. 64, no. 13, p. 1687, 1994.

[10] Q. Dai, M. F. Schubert, M. H. Kim, J. K. Kim, E. F. Schubert, D. D. Koleske, M. H. Crawford, S. R. Lee, a. J. Fischer, G. Thaler, and M. a. Banas, "Internal quantum efficiency and nonradiative recombination coefficient of GaInN/GaN multiple quantum wells with different dislocation densities," Appl. Phys. Lett., vol. 94, no. 11, p. 111109 , 2009. 
[11] T. S. Ugahara, H. S. Ato, M. H. Ao, Y. N. Aoi, S. K. Urai, and S. T. Ottori, "Direct Evidence that Dislocations are Non-Radiative Recombination Centers in GaN," Jpn. J. Appl. Phys., vol. 37, no. 4, pp. 398-400, 1998.

[12] N. G. Weimann, L. F. Eastman, D. Doppalapudi, H. M. Ng, and T. D. Moustakas, "Scattering of electrons at threading dislocations in GaN," J. Appl. Phys., vol. 83, no. 7, p. $3656,1998$.

[13] J. H. You, J.-Q. Lu, and H. T. Johnson, "Electron scattering due to threading edge dislocations in n-type wurtzite GaN," J. Appl. Phys., vol. 99, no. 3, p. 033706, 2006.

[14] C. F. Johnston, M. J. Kappers, M. a. Moram, J. L. Hollander, and C. J. Humphreys, "Assessment of defect reduction methods for nonpolar a-plane $\mathrm{GaN}$ grown on r-plane sapphire," J. Cryst. Growth, vol. 311, no. 12, pp. 3295-3299, Jun. 2009.

[15] J. S. Speck, S. F. Chichibu, and G. Editors, "N onpolar and Semipolar Group III Materials," vol. 34, no. May, 2009.

[16] I. Grzegory, "High pressure growth of bulk GaN from solutions in gallium," J. Phys. Condens. Matter, vol. 13, no. 32, pp. 6875-6892, Aug. 2001.

[17] J. Karpinski, J. Jun, and S. Porowski, "EQUILIBRIUM PRESSURE OF N2 OVER GaN AND HIGH PRESSURE SOLUTION GROWTH OF GaN J. KARPINSKI, J. JUN and S. POROWSKI," vol. 66, pp. 1-10, 1984.

[18] H. Morkoç, Handbook of Nitride Semiconductors and Devices. Wiley-VCH, Berlin, 2008, p. 410.

[19] M. Ohring, Materials Science of Thin Films - Deposition and Structure, Second. Academic Press, 2002, p. 418.

[20] Y. Furukama, K. Nakajima, and K. Sato, Advances in Crystal Growth Research. Elsevier Science, 2001, p. 234.

[21] S. J. Rosner, E. C. Carr, M. J. Ludowise, G. Girolami, and H. I. Erikson, "Correlation of cathodoluminescence inhomogeneity with microstructural defects in epitaxial $\mathrm{GaN}$ grown by metalorganic chemical-vapor deposition," Appl. Phys. Lett., vol. 70, no. 4, p. 420, 1997.

[22] M. Razeghi and M. Henini, Optoelectronic Devices: III-Nitrides. Elsevier, 2004, p. 16.

[23] "http://www.kymatech.com/products/bulk-products/c-plane-bulk-gan-substrates/bulkgan-c-plane-detail.”. 
[24] A. C. Jones and M. L. Hitchman, Chemical Vapour Deposition -Precursors, Processes and Applications. RSC Publishing, 2009, p. 6.

[25] H. P. Maruska, "THE PREPARATION AND PROPERTIES OF VAPORDEPOSITED SINGLE-CRYSTAL-LINE GaN,” Appl. Phys. Lett., vol. 15, no. 10, p. $327,1969$.

[26] Yole Developpment, "Market Survey “"Bulk GaN Market.”,”2009.

[27] D. Ehrentraut, E. Meissner, and M. Bockowski, Technology of Gallium Nitride Crystal Growth. Springer, 2010.

[28] C. Hemmingsson, P. P. Paskov, G. Pozina, M. Heuken, B. Schineller, and B. Monemar, "Growth of bulk GaN in a vertical hydride vapour phase epitaxy reactor," Superlattices Microstruct., vol. 40, no. 4-6, pp. 205-213, Oct. 2006.

[29] V. S. Ban, "Mass spectrometric and thermodynamic studies of the CVD of some III-V compounds," J. Cryst. Growth, vol. 17, pp. 19-30, 1972.

[30] H. M. Manasevit, "Single-Crystal Gallium Arsenide on Insulating Substrates," Appl. Phys. Lett., vol. 12, no. 4, p. 156, 1968.

[31] H. M. Manasevit, F. M. Erdmann, and W. I. Simpson, "The Use of Metalorganics in the Preparation of Semiconductor Materials," J. Electrochem. Soc., vol. 118, no. 11, p. 1864, 1971.

[32] S. Nakamura, M. Senoh, and T. Mukai, "P-GaN/N-InGaN/N-GaN DoubleHeterostructure Blue-Light-Emitting Diodes," Jpn. J. Appl. Phys., vol. 32, pp. L8 L11, 1993.

[33] “http://www.ioffe.rssi.ru/SVA/NSM/Semicond/GaN/index.html.”.

[34] "http://www.ioffe.rssi.ru/SVA/NSM/Semicond/Si/index.html.”.

[35] "http://www.ioffe.rssi.ru/SVA/NSM/Semicond/GaAs/index.html.” .

[36] C. R. Abernathy, M. E. Overberg, G. T. Thaler, A. H. Onstine, B. P. Gila, F. Ren, B. Lou, and J. Kim, "New applications for gallium nitride," no. June, pp. 24-31, 2002.

[37] F. Bernardini, V. Fiorentini, and D. Vanderbilt, "Spontaneous polarization and piezoelectric constants of III-V nitrides," Phys. Rev. B, vol. 56, no. 16, pp. R10024R10027, Oct. 1997.

[38] B. Monemar and G. Pozina, "Group III-nitride based hetero and quantum structures," Prog. Quantum Electron., vol. 24, pp. 239-290, 2000. 
[39] Y. C. Shen, G. O. Mueller, S. Watanabe, N. F. Gardner, a. Munkholm, and M. R. Krames, "Auger recombination in InGaN measured by photoluminescence," Appl. Phys. Lett., vol. 91, no. 14, p. 141101, 2007.

[40] M.-H. Kim, M. F. Schubert, Q. Dai, J. K. Kim, E. F. Schubert, J. Piprek, and Y. Park, "Origin of efficiency droop in GaN-based light-emitting diodes," Appl. Phys. Lett., vol. 91, no. 18, p. 183507, 2007.

[41] T. TAKEUCHI, H. AMANO, and I. AKASAKI, "Theoretical Study of Orientation Dependence of Piezoelectric Effects in Wurtzite Strained GaInN/GaN Heterostructures and Quantum Wells," Jpn. J. Appl. Phys., vol. 39, no. 2, pp. 413-416, 2000.

[42] P. Waltereit, O. Brandt, a Trampert, H. Grahn, J. Menniger, M. Ramsteiner, M. Reiche, and K. Ploog, "Nitride semiconductors free of electrostatic fields for efficient white light-emitting diodes," Nature, vol. 406, no. 6798, pp. 865-8, Aug. 2000.

[43] K. Okamoto, H. Ohta, D. Nakagawa, M. Sonobe, J. Ichihara, and H. Takasu, "Dislocation-Free m -Plane InGaN/GaN Light-Emitting Diodes on m -Plane GaN Single Crystals," Jpn. J. Appl. Phys., vol. 45, no. No. 45, pp. L1197-L1199, Nov. 2006.

[44] D. F. Feezell, M. C. Schmidt, R. M. Farrell, K.-C. Kim, M. Saito, K. Fujito, D. a. Cohen, J. S. Speck, S. P. DenBaars, and S. Nakamura, "AlGaN-Cladding-Free Nonpolar InGaN/GaN Laser Diodes,” Jpn. J. Appl. Phys., vol. 46, no. No. 4, pp. L284L286, Mar. 2007.

[45] K. Okamoto, J. Kashiwagi, T. Tanaka, and M. Kubota, "Nonpolar m-plane InGaN multiple quantum well laser diodes with a lasing wavelength of $499.8 \mathrm{~nm}$," Appl. Phys. Lett., vol. 94, no. 7, p. 071105, 2009.

[46] H. Wang, C. Chen, Z. Gong, J. Zhang, M. Gaevski, M. Su, J. Yang, and M. A. Khan, "Anisotropic structural characteristics of (1120) GaN templates and coalesced epitaxial lateral overgrown films deposited on (1012) sapphire," Appl. Phys. Lett., vol. 84, no. 4, p. 499, 2004.

[47] Q. Sun, S.-Y. Kwon, Z. Ren, J. Han, T. Onuma, S. F. Chichibu, and S. Wang, "Microstructural evolution in m-plane GaN growth on m-plane SiC," Appl. Phys. Lett., vol. 92, no. 5, p. 051112, 2008.

[48] B. a. Haskell, A. Chakraborty, F. Wu, H. Sasano, P. T. Fini, S. P. Denbaars, J. S. Speck, and S. Nakamura, "Microstructure and enhanced morphology of planar nonpolar m-plane GaN grown by hydride vapor phase epitaxy," J. Electron. Mater., vol. 34, no. 4, pp. 357-360, Apr. 2005. 
[49] S. Strite, "GaN, AlN, and InN: A review," J. Vac. Sci. Technol. B Microelectron. Nanom. Struct., vol. 10, no. 4, p. 1237, Jul. 1992.

[50] S. Nakamura, M. Senoh, and T. Mukai, "Highly P-Typed Mg-Doped GaN Films Grown with GaN Buffer Layers,” Jpn. J. Appl. Phys., pp. L1708-L1711, 1991.

[51] P. Bogusławski and J. Bernholc, "Doping properties of C, Si, and Ge impurities in GaN and AlN," Phys. Rev. B, vol. 56, no. 15, pp. 9496-9505, Oct. 1997.

[52] W. Moore, J. Freitas, S. Lee, S. Park, and J. Han, "Magneto-optical studies of freestanding hydride-vapor-phase epitaxial GaN," Phys. Rev. B, vol. 65, no. 8, p. 081201, Feb. 2002.

[53] A. F. Wright, "Substitutional and interstitial carbon in wurtzite GaN," J. Appl. Phys., vol. 92 , no. 5 , p. $2575,2002$.

[54] J. B. Webb, H. Tang, S. Rolfe, and J. a. Bardwell, "Semi-insulating C-doped GaN and high-mobility AlGaN/GaN heterostructures grown by ammonia molecular beam epitaxy," Appl. Phys. Lett., vol. 75, no. 7, p. 953, 1999.

[55] W. Götz, N. M. Johnson, C. Chen, H. Liu, C. Kuo, and W. Imler, "Activation energies of Si donors in GaN,” Appl. Phys. Lett., vol. 68, no. 22, p. 3144, 1996.

[56] C. I. Harris, B. Monemar, H. Amano, and I. Akasaki, "Exciton lifetimes in GaN and GaInN,” Appl. Phys. Lett., vol. 67, no. 6, p. 840, 1995.

[57] R. Ste, "Symmetry of excitons in GaN," Phys. Rev. B, vol. 60, no. 7, pp. 4438-4441, 1999.

[58] a. Rodina, M. Dietrich, a. Göldner, L. Eckey, a. Hoffmann, A. Efros, M. Rosen, and B. Meyer, "Free excitons in wurtzite GaN," Phys. Rev. B, vol. 64, no. 11, p. 115204, Aug. 2001.

[59] T. Ogino and M. Aoki, "Mechanism of Yellow Luminescence in GaN," Jpn. J. Appl. Phys., vol. 19, no. 12, pp. 2395-2405, 1980.

[60] R. Armitage, W. Hong, Q. Yang, H. Feick, J. Gebauer, E. R. Weber, S. Hautakangas, and K. Saarinen, "Contributions from gallium vacancies and carbon-related defects to the 'yellow luminescence' in GaN," Appl. Phys. Lett., vol. 82, no. 20, p. 3457, 2003.

[61] K. Kuriyama, H. Kondo, and M. Okada, "A point defect complex related to the yellow luminescence in electron irradiated GaN," Solid State Commun., vol. 119, no. 10-11, pp. 559-562, Aug. 2001. 
[62] X. Li, P. W. Bohn, and J. J. Coleman, "Impurity states are the origin of yellow-band emission in $\mathrm{GaN}$ structures produced by epitaxial lateral overgrowth," Appl. Phys. Lett., vol. 75, no. 26, p. 4049, 1999.

[63] H. Z. Xu, a. Bell, Z. G. Wang, Y. Okada, M. Kawabe, I. Harrison, and C. T. Foxon, "Competition between band gap and yellow luminescence in undoped GaN grown by MOVPE on sapphire substrate," J. Cryst. Growth, vol. 222, no. 1-2, pp. 96-103, Jan. 2001.

[64] D. Zakharov, Z. Liliental-Weber, B. Wagner, Z. Reitmeier, E. Preble, and R. Davis, "Structural TEM study of nonpolar a-plane gallium nitride grown on (112-0)4H-SiC by organometallic vapor phase epitaxy," Phys. Rev. B, vol. 71, no. 23, pp. 1-9, Jun. 2005.

[65] S. K. Mathis, a. E. Romanov, L. F. Chen, G. E. Beltz, W. Pompe, and J. S. Speck, "Modeling of Threading Dislocation Reduction in Growing GaN Layers," Phys. Status Solidi, vol. 179, no. 1, pp. 125-145, May 2000.

[66] A. Chakraborty, B. a. Haskell, S. Keller, J. S. Speck, S. P. Denbaars, S. Nakamura, and U. K. Mishra, "Demonstration of Nonpolar m -Plane InGaN/GaN Light-Emitting Diodes on Free-Standing m -Plane GaN Substrates," Jpn. J. Appl. Phys., vol. 44, no. No. 5, pp. L173-L175, Jan. 2005.

[67] M. J. Kappers, M. a. Moram, D. V. Sridhara Rao, C. McAleese, and C. J. Humphreys, "Low dislocation density GaN growth on high-temperature AlN buffer layers on (0001) sapphire," J. Cryst. Growth, vol. 312, no. 3, pp. 363-367, Jan. 2010.

[68] X. H. Wu, L. M. Brown, D. Kapolnek, S. Keller, B. Keller, S. P. DenBaars, and J. S. Speck, "Defect structure of metal-organic chemical vapor deposition-grown epitaxial (0001) GaN/Al2O3,” J. Appl. Phys., vol. 80, no. 6, p. 3228, 1996.

[69] M. a Moram and M. E. Vickers, "X-ray diffraction of III-nitrides," Reports Prog. Phys., vol. 72, no. 3, p. 036502, Mar. 2009.

[70] X. J. Ning, F. R. Chien, and P. Pirouz, "Growth defects in GaN films on sapphire: The probable origin of threading dislocations," no. 0001, 1996.

[71] X. . Wu, P. Fini, E. . Tarsa, B. Heying, S. Keller, U. . Mishra, S. . DenBaars, and J. . Speck, "Dislocation generation in GaN heteroepitaxy," J. Cryst. Growth, vol. 189-190, pp. 231-243, Jun. 1998.

[72] V. Narayanan, K. Lorenz, W. Kim, and S. Mahajan, "Origins of threading dislocations in GaN epitaxial layers grown on sapphire by metalorganic chemical vapor deposition," Appl. Phys. Lett., vol. 78, no. 11, p. 1544, 2001. 
[73] B. Beaumont and P. Venne, "Epitaxial Lateral Overgrowth of GaN," vol. 43, no. 1, pp. $1-43,2001$.

[74] M. a. Moram, M. J. Kappers, Y. Zhang, Z. H. Barber, and C. J. Humphreys, "Very low dislocation density, resistive $\mathrm{GaN}$ films obtained using transition metal nitride interlayers," Phys. Status Solidi, vol. 205, no. 5, pp. 1064-1066, May 2008.

[75] R. Liu, A. Bell, F. A. Ponce, C. Q. Chen, J. W. Yang, and M. a. Khan, "Luminescence from stacking faults in gallium nitride," Appl. Phys. Lett., vol. 86, no. 2, p. 021908, 2005.

[76] D. Hull and D. J. Bacon, Introduction to dislocations, 5th Editio. Elsevier, 2011, pp. $110-112$.

[77] Z. Z. Bandic and T. C. Mcgill, "Electronic structure of GaN stacking faults," Phys. Rev. B, vol. 56, no. 7, pp. 3564-3566, 1997.

[78] D. B. Williams and C. B. Carter, Transmission electron microscopy: a textbook for materials science. Springer, 2009.

[79] K. Thompson, D. Lawrence, D. J. Larson, J. D. Olson, T. F. Kelly, and B. Gorman, "In situ site-specific specimen preparation for atom probe tomography.," Ultramicroscopy, vol. 107, no. 2-3, pp. 131-9, 2007. 


\section{Included Papers}

The articles associated with this thesis have been removed for copyright reasons. For more details about these see:

http://urn.kb.se/resolve?urn=urn:nbn:se:liu:diva-100760 